Two Case Studies in Energy Efficient Renovation of Multi-family Housing
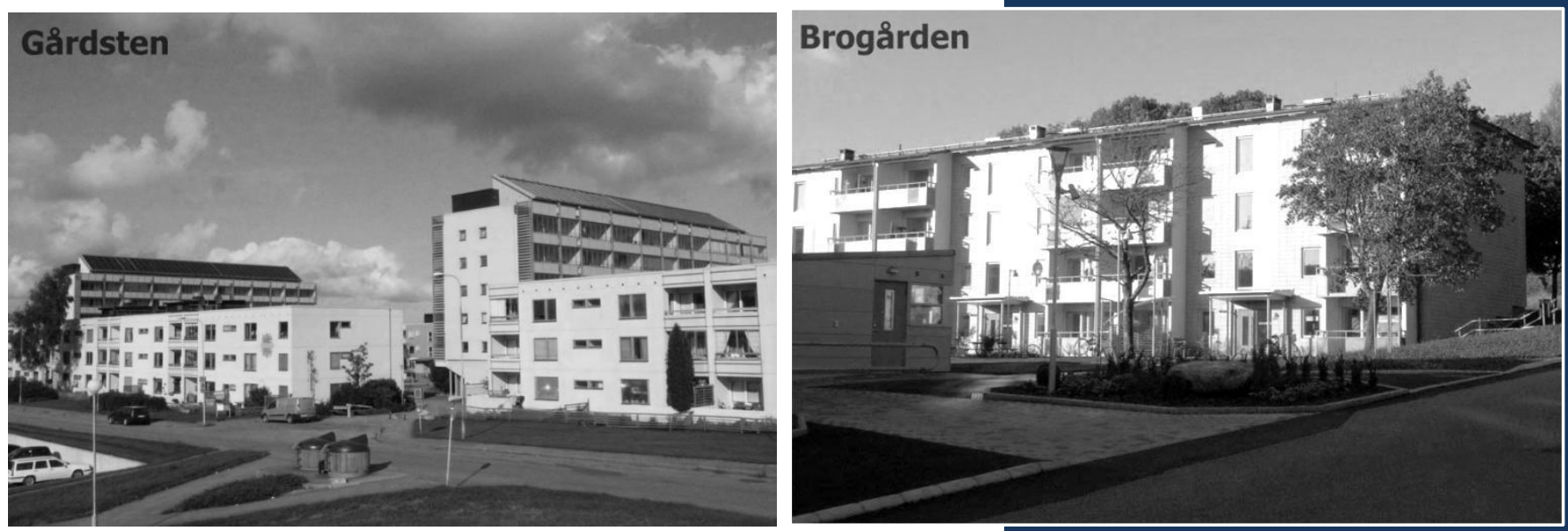

Explaining Robustness as a Characteristic to Assess Long-term Sustainability

Master Thesis at Chalmers Architecture Design for Sustainable Development (MPDSD) 

THESIS FOR THE DEGREE OF MASTER OF SIENCE

Two Case Studies in Energy Efficient Renovation of Multi-family Housing;

Explaining Robustness as a Characteristic to Assess Long-term Sustainability

\author{
VAHID SABOURI
}

Department of Architecture

CHALMERS UNIVERSITY OF TECHNOLOGY

Gothenburg, Sweden 2012 


\section{Two Case Studies in Energy Efficient Renovation of Multi-family Housing; \\ Explaining Robustness as a Characteristic to Assess Long-term Sustainability \\ Vahid Sabouri}

(C) VAHID SABOURI, 2012

Master Thesis at Chalmers University of Technology

Supervisor and Examiner: Dr. Paula Femenías

Design for Sustainable Development (MPDSD)

Department of Architecture

Chalmers University of Technology

SE-412 96 Gothenburg

Sweden

Telephone + $46(0) 31-7721000$

Cover:

[To the left: Low-rise and high-rise buildings in Gårdsten with integrated solar panels on top,

To the right: Passive houses in Brogården with new balconies outside the buildings envelope] 


\section{Abstract}

This study addresses two energy efficiency approaches to renovation of multi-family housing in Sweden aiming at a better understanding of robustness as a building characteristic especially in terms of energy performance of buildings and indoor environmental quality. The study includes a theoretical part where the concept of robustness has been investigated in technical and socio-technical systems and analogously in architectural design. It also includes two case studies as the empirical material of the research. Solar houses in Gårdsten and passive houses in Brogården have been chosen as two different approaches to renovation of multi-family housing with energy efficiency objectives. Finally, the two cases have been analyzed using an analytical framework which has been developed based on the findings of this research study to assess the robustness of applied energy efficiency measures.

The performance of some systems in operational situation is not the same as their expected performance during the design phase. This could be caused by poor assumptions during modeling or disregarding users' behavior. In case of energy efficient buildings such misestimation can result in vulnerable measures which would affect energy objectives of the design. Thus, to achieve sustainable architecture especially in a long-term perspective, applying more robust measures (measures which are not sensitive to probable future changes) would reduce vulnerability of design to unforeseen situations and enhance durability and reliability of building. So a building could be assessed for robustness of design from different aspects such as robustness of structure and building elements, robustness of users' comfort and satisfaction and robustness of feasible operation and maintenance each of which could enhance robustness of the whole building as a unified system. Concerning energy performance of a building, robustness could be enhanced applying user-oriented and climate-oriented design approaches which increase the adaptability of design to unforeseen future situations.

In the empirical studies the focus has been mainly on the technical aspects. However, in the case analysis, the user-building interface has been also highlighted as an important factor affecting robustness of technical systems. In Gårdsten, the renovation proposal is mostly based on solar gain through solutions such as glazed balconies and solar panels while in Brogarden the approach is based on the concept of passive housing and the result is highly insulated, air tight buildings.

In the analysis, it has been tried to assess long-term sustainability of the cases through a qualitative method. Thus, the cases have been analyzed based on some criteria of robust design and seven major factors (HOMETEC factors) which are more likely to change during a building's life time.

Keywords: Robustness, Energy efficiency, Sustainable buildings, multi-family housing, Renovation 


\section{Acknowledgement}

This master thesis work has been accomplished by help of individuals that I am truly indebted to all of them and would like to hereby thank them. First of all I owe my deepest gratitude to my examiner and supervisor Dr. Paula Femenías whose encouragement, guidance and support from the initial to the final stage of the project made it possible for me to develop an in-depth understanding of the subject. It was through her patience and personal enthusiasm that I could become familiar with research methods and skills in general and also acquainted with the subject specifically. Dr. Femenías not only helped me to find my way and formulate the research approach through our discussions but also supported me by introducing useful relevant materials and references and her valuable comments.

This is also an honor for me to warmly thank Dr. Lena Falkheden especially for her supportive attitude in every situation which makes her a unique honorable person to me. I have always appreciated her constructive suggestions during my studies at Chalmers.

I am grateful to Mr. Christer Nordström and his colleagues in CNA architects who shared their experiences from Gårdsten with me and provided me with essential information and materials in the case study. I am also thankful to Mr. Hans Eek for his vital information about Brogården project and his time for the study visit to the show apartment in the area and passive house centrum in Alingsås.

Furthermore, I would like to thank Professor Kees Van Der Linden and Mr. Stanley Kurvers at TU Delft for their prompt answer to my request and providing me with some supplementary materials on the subject.

Lastly, I should thank my friends and family and especially my kind wife Lida for their encouragement and intellectual support. 


\section{Table of Contents}

Abstract ........................................................................................................................... II

Acknowledgement....................................................................................................................II

Table of Contents....................................................................................................................IV

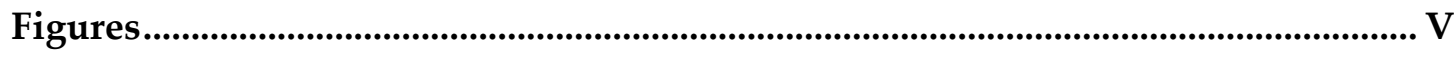

Tables ..................................................................................................................

1. Introduction ............................................................................................................... 1

1.1. Sustainable development and sustainable buildings ..................................................... 1

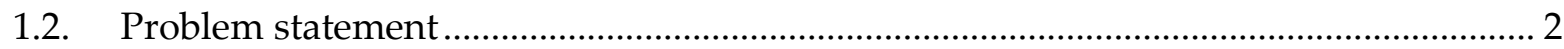

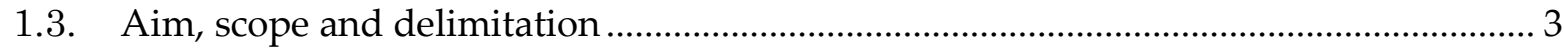

1.4. Research questions ………………………………................................................ 4

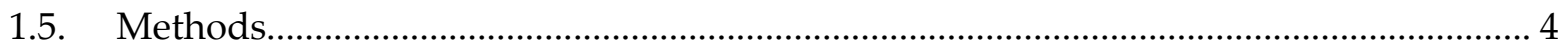

1.6. Analytical framework ............................................................................................. 5

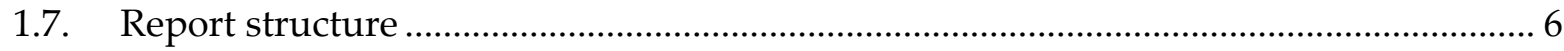

2. Robust design ....................................................................................................................... 6

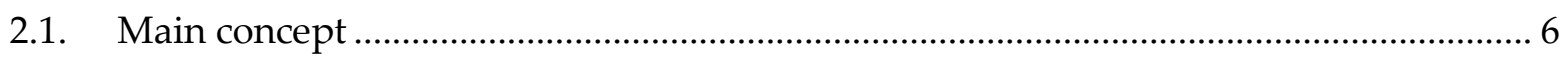

2.1.1. Robustness in technical systems .............................................................................. 7

2.1.2. Robustness in socio-technical systems.................................................................... 10

2.2. Robustness and building design............................................................................... 11

2.2.1. Robustness of structure and building elements ..................................................... 12

2.2.2. Robustness of users' comfort and satisfaction ........................................................ 14

2.2.3. Robustness of feasible operation and maintenance ................................................. 16

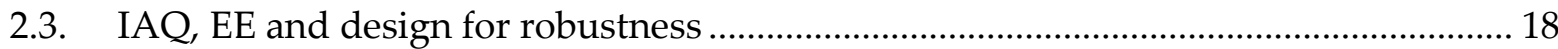

3. Energy efficient approaches to renovation of multi-family housing in Sweden22

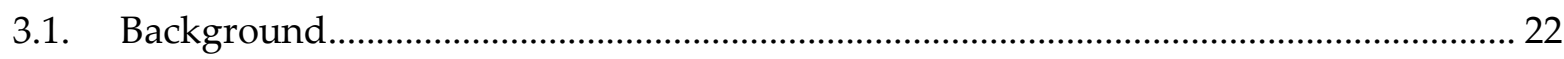

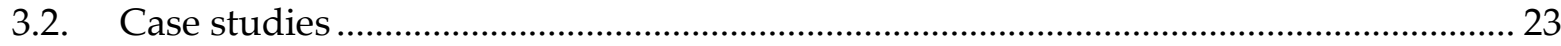

3.2.1. Solar Houses, Gårdsten, Göteborg ………………………………………………...... 23

3.2.2. Passive houses, Brogården, Alingsås...………………………………………………. 32

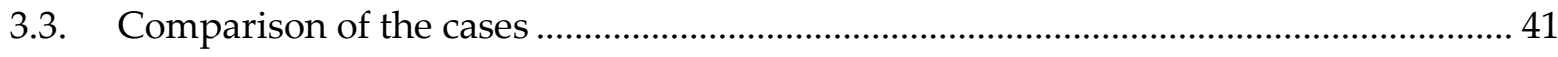


4. Analysis of the cases .....................................................................................................42

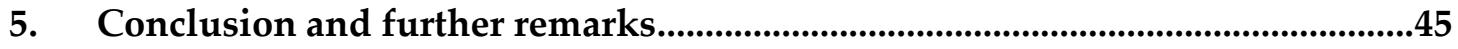

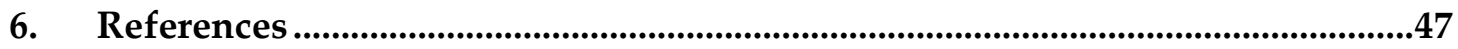

\section{Figures}

Figure 1: The traditional hierarchy of availability (Andersson, 1997) .........................................7

Figure 2: Dependability and its subareas (Andersson, 1997) .......................................................

Figure 3: The technical process according to Hubka and Eder ..................................................9

Figure 4: Andersson's View of the relation between robustness and dependability of technical

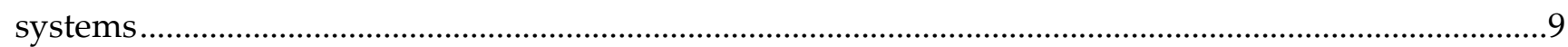

Figure 5: Different layers of a building (Brand, 1994) ............................................................14

Figure 6: Energy consumption in different sectors (Laustsen, 2008, P. 7) .................................17

Figure 7: Situation of Solar houses in Gårdsten......................................................................24

Figure 8: Unpleasant gray façades of buildings, Gårdsten before renovation ...........................25

Figure 9: Poor quality of outdoor environment, Gårdsten before renovation ............................25

Figure 10: First phase of solar houses, 10 buildings in three blocks ...........................................26

Figure 11: Enclosing the previous balconies of high-rises in Gårdsten with glazed panels.......27

Figure 12: Ventilation system of high-rises in Gårdsten before and after renovation ................28

Figure 13: Greenhouses as communal spaces in the ground floor of high-rises, solar houses I29

Figure 14: Greenhouses adjacent to laundry rooms in the ground floor of high-rises, solar houses I

Figure 15: Courtyards being protected against strong winds by greenhouses in solar houses I

Figure 16: Ventilation system of low-rises in Gårdsten before and after renovation..................30

Figure 17: Heating system of exterior walls in the low-rise facing south, solar houses I ............31

Figure 18: Solar panels installed on the southern facade of the low-rise, solar houses I............31

Figure 19: Situation of Brogården in Alingsås ............................................................................32

Figure 20: Building blocks in Brogården..................................................................................32

Figure 21: Pleasant appearance of the buildings and the environment in Brogarden before renovation .33

Figure 22: Poor condition of brick facades in Brogården before renovation ..............................34

Figure 23: Typical lay out of apartment units in the buildings in Brogården ............................35

Figure 24: Insulation of the ground slabs in Brogården buildings .............................................36

Figure 25: Installation of the new facade tiles in Brogården renovation.....................................37

Figure 26: New balconies constructed outside of the buildings envelope in Brogården............38

Figure 27: System of heat recovery in heat exchangers used in Brogården.................................39 
Figure 28: Air inlet in a bed room in Brogården after renovation............................................ 40

Figure 29: Air outlet in a kitchen in Brogården after renovation ............................................... 40

Figure 30: Relation between main objectives of EE buildings, robustness criteria and

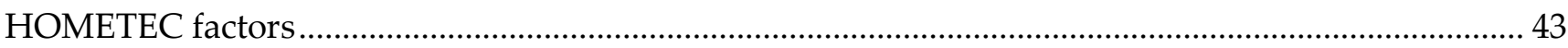

\section{Tables}

Table 1: A comparison of the U-value of building elements in Brogården............................... 38

Table 2: Comparison of some results in Gårdsten and Brogården.............................................. 41

Table 3: Analysis of the cases based on the criteria of robust design and major factors of

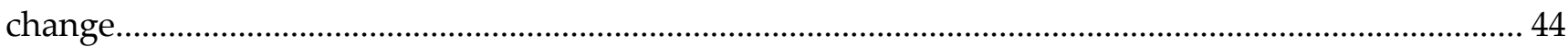





\section{Introduction}

\subsection{Sustainable development and sustainable buildings}

According to the most often-quoted definition of sustainable development, coined by the UN World Commission on Environment and Development in their report, Our Common Future, which is also known as The Brundtland Report, 'sustainable development is development that meets the needs of the present without compromising the ability of future generations to meet their own needs...'(WCED, 1987). The concept by its definition encompasses a wide range of domains and thus many various fields of science should be involved to achieve the goal. As it is stressed in 'Adaptation to climate change; a spatial challenge' (Roggema, 2009), global warming and change of climate is likely to be the most critical problem of the 21st century. Although efforts have been made to reduce $\mathrm{CO} 2$ emissions it is agreed that even in case of succeeding to minimize this phenomenon, the negative consequences of the changes so far, will continue and affect different systems at least for a few decades. Tin (2008) explains that changes in the climate are happening faster and stronger than expected. This means that it is not possible to predict the future and we might face substantial uncertainties. Thus, adaptation to changes seems inevitable. According to Roggema (2009), the best strategy is to get ready for facing the worst case scenario to be able to deal with probable serious changes in close future.

Today buildings play a significant role in development of most societies and not only a substantial amount of financial resources are spent in this sector but also buildings are responsible for almost 40 percent of total energy consumption and 16 percent of fresh water annually. The construction industry is also responsible for depletion of 40 percent of raw stone, gravel and sand and 25 percent of the world's virgin wood (Dutil et al., 2011). According to USGBC in the United States buildings are responsible for 39 percent of $\mathrm{CO} 2$ emissions. These figures can be strong evidence that building architecture have a substantial impact on sustainable development both from economic and environmental point of view. On the other hand, with the close relation of people and architecture and the large amount of research carried out on the effect of architecture on feeling, health, communication and behavior of people etc., there would be no doubt about the role of architecture in social sustainability.

Sustainable building is a term which is usually used to stress the objectives of sustainable development in relation to building activities and the built environment (Femenias, 2004). Since buildings are responsible for environmental issues such as $\mathrm{CO} 2$ emissions and consequently climate change, sustainable buildings are characterized partly by having less impact on the environment. However, the other side could be how well these buildings withstand the environmental conditions and adapt to future situations. Although there is no globally accepted definition for sustainable building and it is not realistic to expect such a definition because of 
diverse contexts, conditions and priorities in each project, as Femenias (2004) explains, for implementation of sustainable building it is suggested to consider several factors including a lifecycle systemic approach for different stages from planning to maintenance and even demolition of buildings in order to prolong the life span of the design and make it more flexible and adaptable. Thus, regarding sustainability in spatial planning and architecture, urban landscapes, spatial functions and buildings should be designed in a way that they are capable of dealing with unforeseen situations.

\subsection{Problem statement}

As previously mentioned, buildings are responsible for a considerable percentage of the world's total energy consumption. Nowadays in many countries there is a growing tendency towards strict energy consumption targets in building codes and energy efficiency standards (Simm et al., 2011). Thus, during the past recent years there have been efforts, especially in Europe, to design and build energy efficient buildings or renovate the existing housing stock into energy efficient housing in order to optimize buildings' energy consumption. In some cases the results have been reported to be satisfactory especially in the first few years after the buildings were occupied. However, in some other cases energy efficiency measures have been vulnerable to factors such as aging, maintenance requirements or users' behavior etc (Wigington, 2008).

The performance of some systems in a real life situation is not the same as their expected performance on the drawing board or in the test chamber (Leyten et al., 2005). This discrepancy between the predicted design performance and what will happen during the real life operation of a building can considerably influence the energy efficiency objectives of the building (Simm et al., 2011). Among other reasons, poor assumptions regarding the performance of the building and installations during modeling which can mislead the designers in their approach and occupants' behavior could be mentioned as two commonly cited causes for such a performance gap (Simm et al., 2011 with refer to Raslan et al., 2009, Masoso, 2009 and Torcellini et al., 2004). As for HVAC systems which are in a close relation to energy savings in a building, some factors including sensitivity to aberration from design assumptions, unfeasible maintenance requirements and lack of transparency to occupants and building management account for such vulnerability of measures and goals (Leyten et al., 2005). Furthermore, more technically sophisticated systems which are increasingly applied in active design approaches are more likely to be fragile due to their dependency on technology (Leyten et al., 2005) and could easily affect energy efficiency of buildings.

On the other hand, measures improving energy efficiency do not always result in the anticipated energy savings since part of the savings might be offset through other mechanisms (Gonzalez, 2011). This phenomenon is referred to as the 'rebound effect' in literature and energy efficiency debates and is partly caused by overestimating energy-saving potentials and under- 
estimating saving costs. Such misestimation is mostly due to disregarding the impact of users' behavior (Haas et al., 2000). Especially if the use of any type of energy and natural resource or other inputs such as labor is considered, the system sometimes deviates from its efficient use of energy or economic objectives to a large extent. This can make efficiency measures economically vulnerable even if from some other points of view they are still beneficial.

Consequently, in achieving sustainable architecture, energy efficient buildings which are dependent on sensitive measures are not desirable results in a long-term perspective and designers should plan for buildings with reduced vulnerability to unexpected changes. Here the notion of resilience or robustness, which could be simply explained as the ability of a system to keep on working properly, despite of changes in the design assumptions, can enrich buildings characteristics and fill the gap. For a better understanding of the concept it should be noted that the term vulnerable is defined as exposed to the possibility of being attacked or harmed (Oxford dictionary) or open to attack or damage (Merriam-Webster dictionary) and here by a vulnerable system we mean a sensitive system which is open to be damaged or is easily pushed to an undesired situation.

A simple comparison of the definitions of sustainability and robustness clarifies that sustainable building approach is totally in sync with the description of robust system design. Firstly both notions aim at more durable systems and secondly they have a common ambition of creating systems adaptable to future situations (see section 2). Consequently, aiming for robustness in building design would perfectly support its sustainability which is a broader concept. It has been reflected in an essay titled 'The sustainability of beauty' on Partridge Partners website (see references) that sustainability is bequeathed by longevity and longevity is resulted from robustness.

\subsection{Aim, scope and delimitation}

In this research project, energy efficiency approaches to renovation of multi-family housing in Sweden is investigated. Concerning sustainability issues in the housing sector, especially of economic and environmental aspects, renovation of existing housing stock is considered as a significant contribution to substantial savings in new construction costs, natural resources and energy consumption. Furthermore, when it comes to energy efficiency approaches to renovation of these buildings, this contribution to sustainable development would be more effective. Moreover, It was estimated in the final communique of the third European Ministers' conference on 'Sustainable Housing' that in the next fifty years, the existing housing stock in EU will play a ma-

jor role in the housing sector while the part of newly built units will not be more than $15 \%$ by 2020. According to Boverket, currently less than 50000 new apartments are built each year in Sweden. Therefore the renovation of the housing stock related to the million homes program can be seen as a great opportunity to achieve the objectives of energy efficiency. 
This study aims at a better understanding of robustness as a building characteristic, especially in terms of energy efficiency measures, indoor air quality (IAQ) and users' comfort. In order to fulfil this goal the concept of robustness is addressed through a theoretical approach and an empirical analysis of two cases applying a qualitative method. The case studies are carried out with the main focus on energy efficiency measures to understand which solutions regarding IAQ result in a more robust design.

The study addresses energy efficient renovation of multi-family housing and its focus is on the criteria by which the robustness of design would be assessed. Although it has been tried to provide a general definition of robustness in building design and investigate robust design from different points of view in architecture, the study limits its coverage on the one hand on multi-family housing renovation and on the other hand on robustness of measures influencing energy efficiency of building and related issues such as indoor environmental quality and users' comfort. It is also worth mentioning that the projects chosen for case studies have been two different approaches to energy efficient renovation which were carried out in Sweden as demonstration projects and thus most measures which have been addressed are the ones applicable in Sweden or countries with a similar climate.

\subsection{Research questions}

In the present research study it has been tried to find answers to general questions such as:

- How can robustness be defined as a characteristic in architectural design?

- What are the related issues and factors influencing robustness of a building?

Moreover, the study has particularly focused on energy efficiency measures in multifamily housing renovation and has tried to answer underlying questions such as:

- How can the concept of robustness be applied to assess sustainable architecture?

- What energy efficiency measures can enhance the robustness of design in renovation of multi-family housing?

\subsection{Methods}

In this research which aims at investigating the concept of robustness as a characteristic of some various properties in a building design and specifically the robustness of energy efficiency measures, the approach undertaken is based on qualitative methods and according to the explanation of Femenías (2004) with refer to Alvesson and Sköldberg (1994), the process can be seen as abduction which is a kind of approach in between deduction and induction. In the book Architectural research methods, Groat and Wang (2002) adapt a matrix from John Cresswell 
and argue the differences between quantitative and qualitative research paradigms. According to this comparison, with an ontological assumption, reality is objective, singular and apart from the researcher in quantitative research while in a qualitative research reality is subjective and multiple as it is seen by the participants in a study. Moreover, on an epistemological level, researcher is considered as independent from the subject of inquiry in a quantitative research. On the other hand, in a qualitative research, the researcher is considered as interactive with the subject of inquiry. And finally, in methodology, quantitative research assumes a deductive process and looks for cause and effect relations, while the qualitative paradigm entails an inductive process and mutual simultaneous shaping of factors are considered as effective on the subject.

In the same book, Groat and Wang first explain different approaches to the literature review and then classify the methods, widely applied in architectural research, into seven main categories including: interpretive-historical research, qualitative research, correlational research, experimental and quasi-experimental research, simulation and modeling, logical argumentation and case study and combined strategies (for more information see Groat and Wang, 2002).

According to Groat and Wang (2002), the methods used for this research are mainly literature review and case studies. However, since to collect data for case studies, different articles and brochures have been studied, secondary data have been used and methods such as interviews and study visits have also been conducted, it could be considered as combined strategies. The material required to undertake this research can be divided to two types of information; theoretical knowledge mostly related to the concept of robustness and how it applies to architectural design and empirical material regarding the built environment and results from previous experiences. The former data was gathered through literature study and the latter was collected by combined strategies.

This would also mean that in the process not only different methods but also different sources have been used which would consequently increase the validity of the research and its findings. This use of multiple methods or multiple sources are respectively referred to as methodological triangulation and data triangulation (See Femenías 2004, p. 120) which together with other types of triangulation significantly affect the validity and applicability of findings. Moreover, in order to strengthen the validity of data in case studies the interviews which were conducted in English were fully recorded to cover any deficiency in English or making notes. It is also worth mentioning that for the literature studies the materials were chosen in different ways.

\subsection{Analytical framework}

In order to assess the cases, an analytical framework has been developed in this study. Since the research has resulted in the importance of user-centered and climate-oriented design 
to achieve robust architecture, the two cases have been mainly analyzed with focus on the criteria of these two design approaches. The analysis has been done with a qualitative method and regarding each criteria the advantages and disadvantages of the cases have been mentioned separately. The criteria applied in this framework have been chosen according to the outcome of the literature study and the delimitation of this study which is renovation projects, bearing in mind the limitations of the research itself.

On the other hand since robust design deals with reduced vulnerability to unforeseen situations, to assess the cases for robustness of EE measures some major factors which are more likely to change during a building lifetime and consequently affect its energy performance have been studied in relation to the aforementioned criteria.

\subsection{Report structure}

This report comprises of three main parts. Section 1 is considered as an introduction to the whole research project. Section 2 and 3 are the study parts of this report, including investigations on the existing knowledge, information and experiences in this field. Literature study as the theoretical material is reflected and argued in section 2 while section 3 addresses the empirical material of this research which is the case studies. Eventually, Sections 4 and 5 are the concluding parts, in which the results from previous sections, an analysis of the cases based on the resulting analytical framework, some reflection, discussion and a sum up of the main debates are provided.

\section{Robust design}

\subsection{Main concept}

In a scientific approach, a correct understanding of a concept, and especially a new one, entails high perception of that concept which is not attained unless one is perfectly acquainted with its definition in that field of science, since considering just the lexical meaning of a word can be variously interpreted.

Although there have been some attempts to define concepts such as 'Robustness' and 'Robust design' in industrial science and the fields related to technical products or sociotechnical systems, it seems that there is still no comprehensive agreed definition for these terms in scientific terminology. On the other hand, in some cases the term 'robustness' might be compared with conceptions such as 'reliability', 'durability' and 'dependability' on one side and 'stability', 'resilience' and 'adaptability' on the other side. The author believes that it is through these comparisons that one can have an accurate interpretation of this notion, alt- 
hough some others might think this relationship would obscure the situation.

It is worth mentioning that despite of all small differences, these definitions are coherent and one would not find contradictions in the concept as a whole. Here the notion is investigated in two different but at the same time similar areas which would be related to the field of architecture and especially building design.

\subsubsection{Robustness in technical systems}

In his Article, Robustness of Technical Systems in Relation to Quality, Reliability and Associated Concepts, Andersson (1997) tries first to clarify the difference between reliability engineering and robust design by providing the definitions of reliability, availability, durability and dependability and how they are all associated with the larger image of Quality.

Andersson refers to the Swedish standard SS 020104 and the British standard BS 4778 which are both based on ISO 8402 and defines reliability as the ability of an item to perform a required function under stated conditions for a stated period of time. It is described how reliability together with maintainability and maintenance support carries the Availability of a technical system which is generally defined as the ability of an item (under combined aspects of its reliability, maintainability and maintenance support) to perform its required function at a stated instant of time or over a stated period of time. (Figure 1)

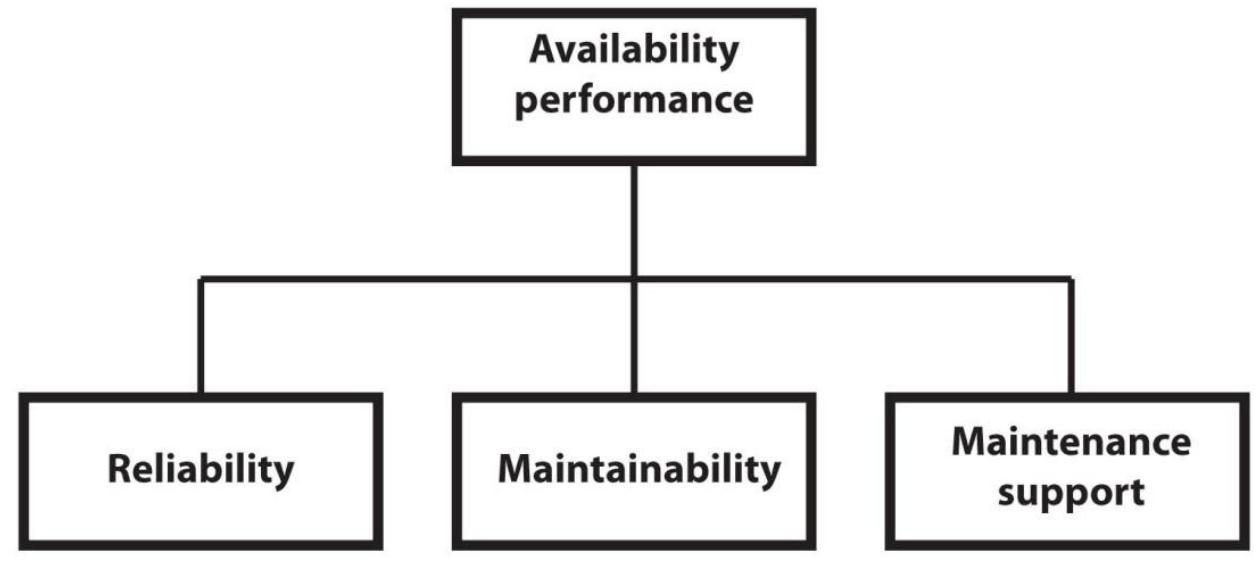

Figure 1: The traditional hierarchy of availability (Andersson, 1997) 
However, Andersson explains that some properties of a product other than those referred to its purpose, for instance those related to aesthetic aspects of it, cannot be subjected to reliability analyses. For example he believes it is a bit odd and clumsy to say that a product has a reliable color and proposes to use the term durability in such cases.

According to figure 2, durability which is defined as the ability to resist the adverse effects of environment, use and maintenance with the progress of time combined with availability would constitute another characteristic for a technical system which is called dependability by some authors.

Then Andersson formulates his definition of robustness in technical systems based on the model of technical process already presented by Hubka and Eder (Figure 3).

The graphic simply states that a technical process through which an operand (material, energy or information) is transformed from one state to another is brought about by a technical system, a human operator and an active environment as the three major operators. If a secondary input (a noise factor) which is usually a disturbance in the active environment, affects the technical process, it might cause unwanted secondary outputs.

Since the technical system is considered as the main operator of the technical process, the aim of robust engineering is to design systems in which unexpected secondary inputs cannot excessively affect the performance of the system and the result of the process.

Consequently, according to Andersson If a technical system maintains a stated performance level of its properties in spite of fluctuations in primary and secondary inputs, the active environment, the operands and in human operation, then the system is robust.

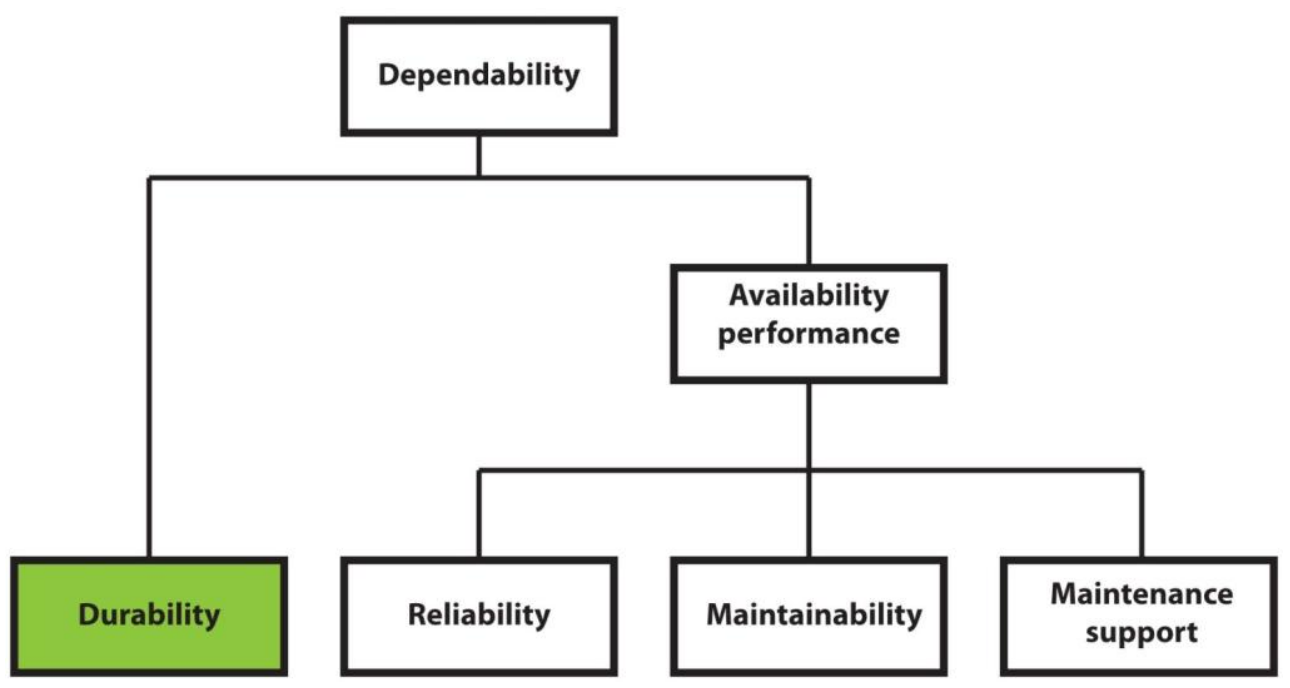

Figure 2: Dependability and its subareas (Andersson, 1997) 


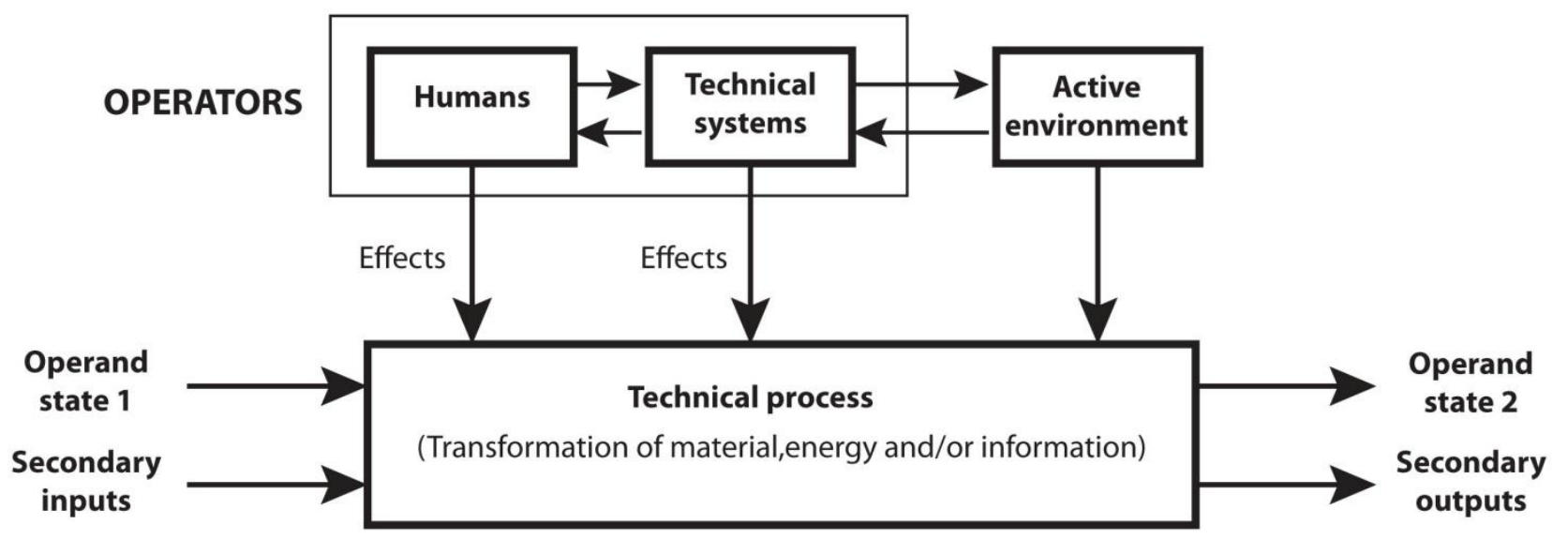

Figure 3: The technical process according to Hubka and Eder

\section{Robustness engineering vs. reliability engineering}

Andersson believes that the main difference between reliability engineering and robust engineering lies in the assumed conditions for the performance of a system. As the definition of reliability implies, reliability engineering deals with some anticipated conditions in a known environment including a set of usual expected variations, while in robustness engineering approach the system should be able to handle other unusual unexpected situations and rare events.

Eventually, Andersson shows his view of how robust design provides means of enhancing the dependability of a technical system on the hierarchy model of product quality (Figure 4) and the article is concluded with two main tasks for a robust design:

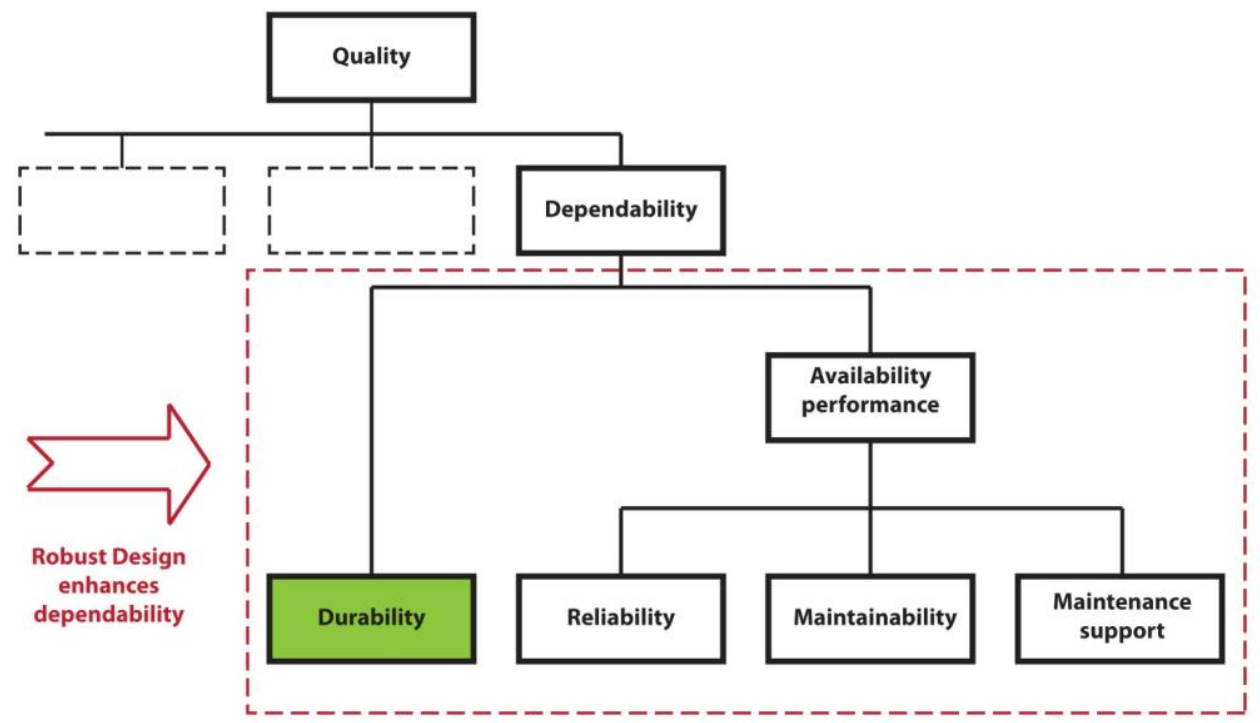

Figure 4: Andersson's View of the relation between robustness and dependability of technical systems 
1. To predict unexpected events that might occur outside the boundaries of the stated conditions

2. To prevent undesired disturbances from affecting the performance of the system or at least to damp their effects on the result of the process

Furthermore, it has been stressed that the concept of robustness could only be applied for those quantifiable properties of a product which can be described as an inputoutput relation and is not applicable to those subjective properties which are mainly dependent on personal taste.

\subsubsection{Robustness in socio-technical systems}

In the paper titled Design of robust socio-technical systems by Pavard et al. (2006) robustness of socio-technical systems is studied mainly by means of comparing the differences between regulation, resilience and robustness within the theoretical framework of complex systems. From this point of view three types of engineering for complex systems has also been presented; Classical engineering, resilience engineering and robustness engineering. According to their discussion (Pavard et al, 2006, p. 2) 'Intuitively, a robust system is one which must be able to adapt its behavior to unforeseen situations, such as a perturbation in the environment, or to internal dysfunctions in the organization of the system, etc.' However, they believe this definition does not perfectly differentiate between robustness and the other concepts of regulation or resilience.

In order to clarify the differences between these notions, three types of regulations are presented:

a) Classic regulations which aim to maintain a constant control over the behavioral variables of the system to guarantee the stability of the system's behavior.

b) Structural regulations which are able to adjust the structure of the system to the new situation by self-adaptation in order to preserve the function of the system.

c) Emergent and self-organized regulations that let the system to govern itself in an emergency situation by self-organization and in association with its environment.

This point of view for managing complex socio-technical systems is followed by introducing three required types of engineering:

1) Classical engineering which is characterized by functional stability and anticipating probable situations. This approach aims for no errors in the performance of the system.

2) Resilience engineering which is characterized by uncertain situations and reduced 
anticipation of the system's behavior. This approach aims for dynamic reorganization to recover the function of the system.

3) Robustness engineering which is characterized by emergent functionalities and no anticipation of further situations. This approach aims for self-organization processes in case of emergent situations.

\section{Robustness engineering vs. resilience engineering}

As implicitly explained, the major difference between these two notions is that resilience engineering deals with undesired situations which are still possible to be anticipated and although changes might happen in the organization of the system, the aim is to preserve a certain result and keep the function of the system alive. This approach by its nature considers the system clearly separated from its environment. However, in robustness engineering, which deals with non-deterministic emergent situations in complex systems, firstly it is not possible to ensure that the function of the system or its subsets will be maintained and secondly the system is not assumed as a distinct entity since there might be a close interaction between the system and its environment and they could be tightly associated.

\subsection{Robustness and building design}

Given the fact that buildings are socio-technical systems consisting of different technical and socio-technical sub-systems which might be interrelated; robustness criteria could be applied in the design approach in order to create more robust buildings. A question might logically arise here; what are the factors or measures which influence the robustness of a building? Partrige partners believe that robustness is the combination of structural strength, flexibility of layout and construction redundancies. However, this question is not easy to be answered shortly and comprehensively. For instance what seems to be lacking in the latter description is user satisfaction which can play a significant role in robustness of a building.

As it has been already indicated a building is a complex system, comprising several sub-systems each of which might be subjected to the concept of robustness and could effectively influence the robustness of the whole system. Nevertheless there is a set of major factors which could be generally considered in the design approach including those, influence more the durability of building structure and elements, those related to the comfort and satisfaction of users in different situations and factors affecting feasibility of building operation and maintenance. 


\subsubsection{Robustness of structure and building elements - Structure}

According to the definition of robustness of technical systems, robustness of building structure seems to be a concept not very difficult to be formulized, however, it is also believed that despite of several researches all around the world on this topic in the past few years, it has been a little understood and widely debated issue which requires more study and investigation (www.aisc.org). A set of studies have been commenced mainly by North America and Europe on development of methodologies to ensure an appropriate level of structural robustness in building structures. The theory of structural reliability is one of the major aspects of these researches (Faber et al, 2011). Although this debate is not in the scope of this research, mentioning some definitions and major concerns of this concept seems to be proper here:

Robustness is the insensibility of a structure to local failure. From this definition follows that the robustness is a property of the structure (Diamantidis, 2009).

A robust structure is one that exhibits the ability to redistribute load and remain stable after localized but severe damage to key elements (www.aisc.org).

Robustness is broadly recognized to be a property which is not only associated with the structure itself but needs to be considered as a product of several indicators; risk, redundancy, ductility, consequences of structural component and system failures, variability of loads and resistances, dependency of failure modes, performance of structural joints, occurrence probabilities of extraordinary loads and environmental exposures, strategies for structural monitoring and maintenance, emergency preparedness and evacuation plans and general structural coherence (Faber et al., 2011).

Since February 2007 the project COST Action TU0601: Robustness of structures has been launched in Europe to exchange information and knowledge in the field of structural robustness in order to set up the foundation for enhanced regulations in design and assessment of structures in Europe. This Action of COST (European Cooperation in Science and Technology) which has been to conclude in October 2011 aims at delivering the fundamental framework, methods and approaches required to guarantee the sufficient degree of robustness of structural systems during their life span and regarding people's security and environmental and economic sustainability (Faber et al., 2011). Results from such researches could help the design of more sustainable building structures not only in new projects but also in retrofitting of existing structures. 


\section{- Materials and installations}

Among many other properties of building materials which should be carefully studied in order to make a good environmental choice, robustness can be an important factor to improve durability and promote building sustainability. However, it should be stressed that it is not an easy process to choose the right material for a construction project due to various criteria involved, different knowledge required and specific conditions of the case. According to Bokalders et al. (2010) some necessary investigations are how materials are produced, how many and what kind of resources are used, how much embodied energy they have, what kind of emissions they release, how indoor environment and users' health are influenced by them, how material usage influence health of workers during construction and what the final residues are. Moreover, the impact of materials on the environment could be studied using life-cycle analysis (LCA) either from cradle to grave or from cradle to cradle since some believe for an ideal sustainability nothing should be thrown away. Bainbridge says: An ideal building would be inexpensive to build, last forever with modest maintenance, but return completely to the earth when abandoned (Dutil et al., 2011, p. 449, 450). Here to evaluate the robustness of materials the definition of robust products (technical systems) seems to be applicable. As an example, regarding some desired characteristics of a building for instance healthy indoor climate, some materials may be considered healthy in a normal situation, but they might have different behaviors in other situations or in combination with other systems. Thus a robustness oriented analysis of materials can help buildings to insist on their desired qualities.

However, one might ask which materials in a construction should be given the priority for high robustness if this is the case? Actually a proper answer to this question depends on different factors such as considering the function of the building or the context where it is going to be built etc., however, generally, according to Chris Alexander (Brand, 1994) more money should be spent on the basic structure and less on finishing. Furthermore, Brand (1994) expresses by the shearing layers of change (Figure 5) that Structure and Skin are the two layers which are expected to last longer (30-300 years and 20 years respectively) thus it is more reasonable to spent money on robust materials for these two elements while Space plan (interior materials) is more likely to change due to fashion or personal tastes of different users. 


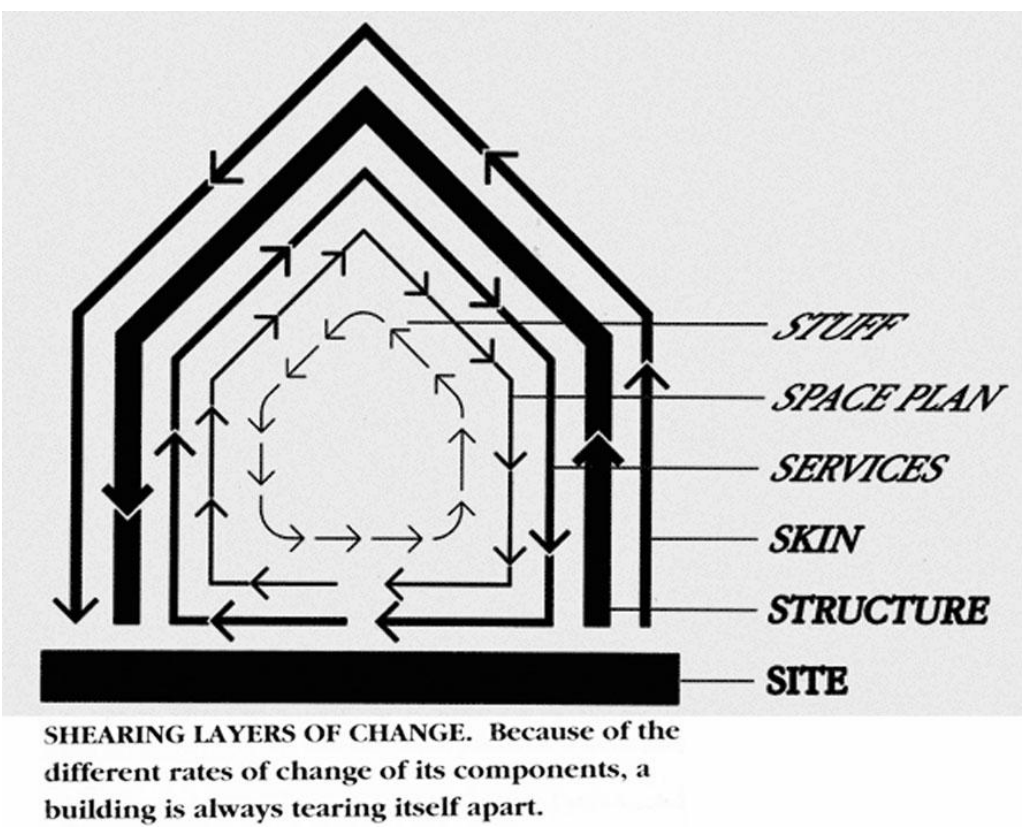

Figure 5: Different layers of a building (Brand, 1994)

\subsubsection{Robustness of users' comfort and satisfaction}

\section{- Indoor environmental quality}

IEQ of a building encompasses indoor air quality (IAQ) as well as thermal comfort, health, safety, quality of potable water and other issues such as lighting, acoustics, ergonomics and electromagnetic frequency levels. It would not be an exaggeration if one says that the success or failure of a building lies on its IEQ. Bokalders et al. (2010) stress that the construction must be done correctly from the beginning since even small mistakes can lead to serious problems. Apart from many other aspects influencing IEQ of a building they highlight management of damp, radon, noise and dirt for a robust healthy building. Although some materials may release unhealthy emissions, in order to have a healthy building it is not enough just to choose healthy materials. As it was previously mentioned, it is also important to have an appropriate combination of them in a set with regard to its intended function and probable future situations (Bokalders et al., 2010).

Furthermore, it has been explained that buildings' services influence indoor climate, among which ventilation system has the largest effect. Heating and cooling systems affect users comfort and electrical systems influence the electro-climate. Water and sewage systems may cause problems if they start to leak or for example if changes in the material of pipes affect the health of potable water. Consequently, robustness of buildings' IEQ in a long term perspective is directly associated with robustness of their services. 


\section{- Functionality of spaces}

Robustness of a building obviously entails the usability of its interior spaces over its lifetime and thereby adaptability to new situations, users and even functions. In the book, how buildings learn, Brand states that a building and its occupants form a system together and in order to reach an appropriate match they have to adapt to each other. Brand also refers to Owen who describes how some times change of dwellers might even lead to breakdowns in some parts of the dwelling (Brand, 1994).

But how is it possible to design a building which is adaptable to arising situations? Some assert that flexibility of layout and spacious designs would be a solution to adaptable architecture. Moore and Lackney (1994) explain that on the abstract level, flexibility refers to the ability of built space to accommodate for unforeseeable changes such as demographic shifts, community needs, or policy mandates' and Monahan (2002) subdivides flexibility to five properties; fluidity, versatility, convertibility, scalability and modifiability to evaluate this quality in built spaces. However, practical implementation of this concept in design and construction can still be debatable. According to Brand buildings could be classified in three groups. Shabby but roomy buildings, with little or even no ornament but a durable structure, which can easily change, adapt and grow over time. These buildings which have been called Low Road are neither appealing nor stylish and considered as the most freeing since actually no one cares about their changes and very simple measures for improvement can enhance their conditions. On the other hand High Road buildings are those large buildings with kind of monumental qualities characterized by long term purpose and care which change differently over time; Buildings which have been built to satisfy their ambitious owners but still serve their users by undergoing changes with regard to human desires during years. While Low Roads are likely to be gutted and rebuilt, High Roads are constantly refined. However, those gorgeous inflexible buildings known as magazine architecture which have been designed mostly with focus on artistic aspects rather than function, are interesting for architects and elegant for those who watch them from distance but not that pleasing for their users. Buildings in this third group, called No Road by Brand, are merely designed for their specific purpose and are thereby disposable due to their immutability.

However, to increase adaptability of a building to different users' demands some design solutions seem to work properly in the long term. Among them are free plan due to free-standing walls, avoiding unnecessary height differences in floors and avoiding installation of services such as pipes in interior walls as much as possible.

\section{- Aesthetic features}

Although it was mentioned that robustness could be applied for quantifiable proper- 
ties of products and not those dependent on personal taste like beauty, there has also been discussions if there is architecture of beauty which is not related to a style or fashion; architecture of which aesthetic features are recognized and admired over ages. It is not an easy question to be answered, since compared with other works of art; the case is quite different with architecture. No one would try to touch or alter a painting or a piece of art in order to improve it, since it is believed that the integrity of the design should be kept untouched to understand the mystery that lies in it. However, in case of architecture apart from natural aging which affects the appearance of buildings and the state of elements and materials, due to the functional aspects and altering demands of users, a building might be subjected to substantial changes or redevelopment to be adapted to the new situation (Partridge Partners website). That is why it seems a bit sophisticated to talk about timeless beauty in the field of building architecture and especially domestic architecture. On the other hand some see beauty from another point of view. For example Buckminster Fuller considers beauty as proposing a right solution for a design problem as he says:

When I am working on a problem I never think about beauty. I only think about how to solve the problem. But when I have finished, if the solution is not beautiful, I know it is wrong.

Some others believe in the endless beauty of simplicity as Isaac Newton say: 'Nature is pleased with simplicity' or to quote Frank Lloyd Wright: 'Simplicity and repose are the qualities that measure the true value of any work of art'. He also states that "'Think simple" as my old master used to say - meaning reduce the whole of its parts into the simplest terms, getting back to first principles' and this is how Leonardo da Vinci thinks about it: 'Simplicity is the ultimate sophistication'.

However, for a building and especially a domestic one to look pleasant to different users during its lifetime and be adaptable to changing tastes in order to be consistent to the objectives of robustness, an idea could be that surface materials such as facades or interior finishing are used in a way that provides the opportunity to be easily removed and replaced without damaging other parts of the construction.

\subsubsection{Robustness of feasible operation and maintenance}

\section{-Energy efficiency}

It is not only the author's belief that robustness of a building entails its energy efficiency in a long term perspective. Energy efficiency regulations in different sectors and energy efficiency requirements in building codes could be taken as evidence for the need of reducing energy consumption in our future society. According to International Energy Agency (IEA) statistics for energy balance (2007 edition) in the period 2004-2005 (Figure 6), 
the total final energy consumption in the world accounts for 7209 Mtoe (Mega Tones Oil Equivalents) out of which residential sector accounts for 1951 Mote i.e. almost $30 \%$ of the final energy use globally (Laustsen, 2008). This shows that residential buildings are largely responsible for their environmental impact and on the other side can greatly contribute to the movement of sustainable development. While buildings are usually constructed for long time periods, in some cases more than a hundred years, in other energy end uses the capital lifetime for improving efficiency would be optimistically a few decades. Although the cost of energy in future is still questionable, buildings with high energy consumption are very likely to be unacceptable in a few decades at least due to their ecological issues. Consequently, it is of utmost importance that buildings are constructed with robust energy efficiency measures, since this will not only make their maintenance economically affordable in the whole building's lifetime but also prevent extra costs in the future to improve their efficiency by applying alternative solutions.

But how can energy efficiency of buildings be robust? According to the definition of robustness, energy efficient measures in a building should be insensitive to changes in the situation or the environment. It should not be dependent on sophisticated technical solutions since the measure would be vulnerable in case of any deterioration or failure in the technology and thus the energy consumption would increase. Juricic (2011) explains with refer to Leyten and Kurvers that complex building systems such as mechanical ventilation or active cooling systems are very likely to cause high energy consumption or lack of thermal comfort to users due to lack of transparency which leads to misuse. Moreover, complex building systems are difficult to be integrated into design process, hard to be modeled and calculated in energy efficiency analysis and very risky in case of any failure in their functions. Therefore being dependent on complex systems is considered as a characteristic which causes a building to be less robust.

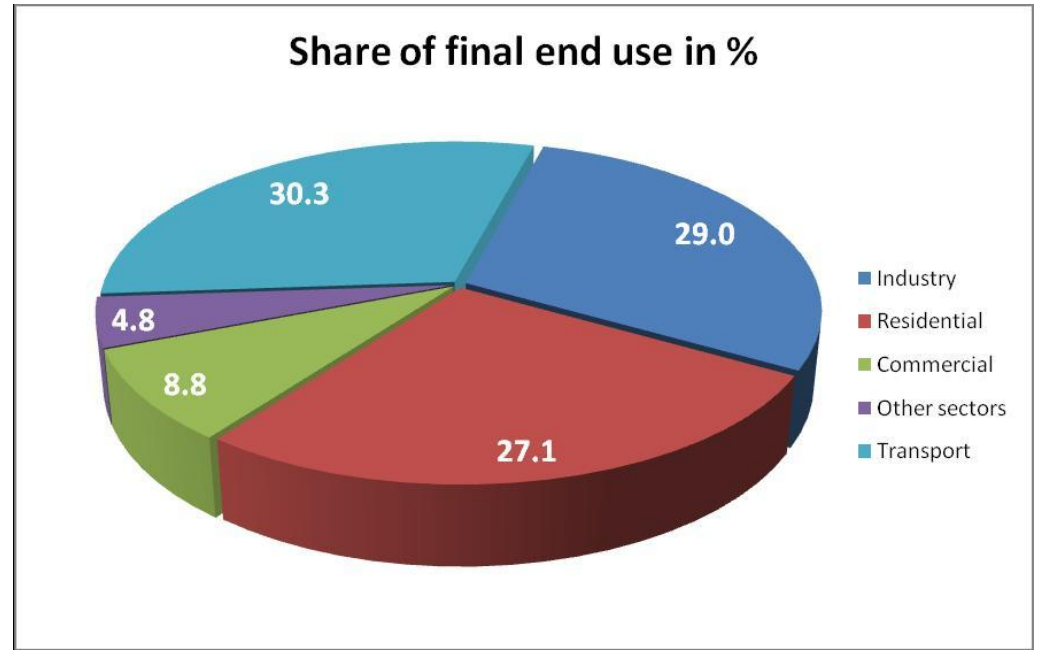

Figure 6: Energy consumption in different sectors (Laustsen, 2008, P. 7) 


\section{-Maintenance facility}

Ease of care and maintenance of buildings is practically and economically influenced by design of details and implementation of different methods (Bokalders et al., 2010). Again to quote Chris Alexander (Brand, 1994) more money should be spent on the basic structure and ceaseless adjustment and maintenance than on finishing. In order for robustness of facile maintenance and care in ecologically constructed buildings, they should be considered in the early planning phase. An important issue regarding maintenance of building services is that they should be easily accessible and adjustable as well as adaptable to new technologies and energy suppliers. According to Brand (Brand, 1994) if the systems are too deeply embedded in the construction they cannot be easily replaced and this has caused many buildings to be demolished earlier than their efficient lifetime.

\subsection{IAQ, EE and design for robustness}

Since the focus of this research is on the robustness of energy efficiency of buildings associated with their IAQ, this part is further investigated. Among other issues of IEQ, IAQ and thermal comfort of users directly influence their satisfaction of indoor spaces and these factors are closely related to the HVAC system(s) of a building.

In their article, Leyten et al. (2005) refer to the definition of robustness of a technique in statistics which is the ability of a certain technique to deliver accurate results, although its assumptions are violated and analogously formulate a definition for robustness of a building and an HVAC system as the measure by which the building or the system lives up to its design purpose in a real life situation (Leyten, 2005). According to previous researches (Leyten et al., 2005, Van Der Linden, 2007) the following factors can cause low robustness in HVAC systems which might lead to indoor climate complaints and unexpected high energy consumption. So it has been suggested to avoid these factors as far as possible:

1. Lack of transparency to occupants and building management

2. Sensitivity to aberrations from design assumptions

3. Unfeasible maintenance requirements

4. Integration of heating and ventilation

5. Regulating supply air volumes

Furthermore, they express that regarding IAQ of a building, in a comparison between low-tech and high-tech solutions, less technically complicated buildings are often more robust. They also provide practical measures to design buildings with high robustness 
regarding HVAC systems. These measures which all help reduce energy consumption, if applied properly, include:

- Integration of building design with occupants' behavior

- Preference for building physics over HVAC to control IEQ

- Preference for free running above air-conditioned buildings

- Control of heat sources and a preference for free cooling

- Separation of heating and ventilation

- Strict control of pollution sources, including humidifiers

- Preference for radiant heating over all air systems

For instance, experiences indicate that people would prefer buildings without cooling but with operable windows to those with fixed windows and cooling systems and they even accept temperatures higher than the comfort range in the former case (Dear et al., 1997). Leyten et al. (2009), though studying office buildings, stress that users control over IEQ such as control over natural ventilation, temperature, sun shading and artificial lighting increases robustness of building. This is because users get the opportunity to adapt IEQ to their specific personal preferences and probable malfunctioning of the building will be compensated. Such justification can also be true in case of residential buildings. Juricic (2011) points to redundancy of systems and multiplicity of functions as a building characteristic which helps its robustness. It has been explained in her master thesis, how one system, several functions is the worst case while several systems, one function could be the best case. Juricic refers to a metaphor developed by Sussman explaining such a concept in natural systems such as in human body where several functions are fulfilled by different organs or some other organs might be adapted to achieve the goal in case of failure in the main organs. This concept has been also compared to building systems by Van Den Ham, Leyten and Kurvers. They have expressed that if one function is fulfilled by several systems in a building, the building is more robust than if several functions are achieved by one system (Juricic, 2011). According to researches done in Delft University of Technology (Linden, 2007), robustness of buildings can generally be improved through user oriented and climate oriented design approaches. Here these two approaches are briefly explained.

\section{User oriented design}

According to Kahraman (2009) with refer to Norman and draper (1986); the term user centered design (UCD) was initially used in the 1980s in university of California in the field of human-computer interaction. This approach which has recently become more common is a de- 
sign approach with focus on the active involvement of users in all stages of the design process in order to improve the efficiency, effectiveness and safety of products. The main difference of this design philosophy with other approaches is that in UCD the product is optimized by giving considerable attention to the demands, wishes and limitations of end users of a product rather than trying to oblige users to change their behavior in order to use the product. UCD aims at more satisfied users by creating products which are usable with minimum effort and optimum efficiency. User experience (UX) is another term used in this area which is described by 'The User Experienced Network' as the quality of experience a person has when interacting with a specific design. In user experience design approach the focus is not only on the efficiency of form and function of products but also the emotional qualities of them (Bullinger et al., 2010). In Architectural products, due to their inherent nature, users are emotionally influenced by created environments significantly. Therefore, as Bullinger et al. (2010) express, applying UCD and UX approaches can be quite advantageous as far as result reliability and enhanced product quality are concerned.

Regarding energy efficient design, users can affect the energy consumption of a building in several ways such as thermal gain, having control over openings and operation of unregulated devices. They might also offset the function of some applied measures by misusing the building (Simm et al., 2011). Thus, in order to aim for a robust design, users' behavior and related factors such as their thermal comfort should be well studied and investigated.

Different methods might be applied to gather information on users' points of view, demands and satisfaction and behavior in the design process. It is not the focus of this research to introduce all methods of this approach; however two general methods in architectural design are mentioned as examples. Participatory design (PD) which has been introduced in the area of architecture especially since 1970s (Bullinger et al., 2010), is a method in which users are given the opportunity to directly influence design and final result by being actively involved in design and construction process. Another method which is quite common in usability engineering (UE) is to set up a process in which actual users test iterative prototypes and are asked to comment on the strengths and weaknesses in each step and find essential shortcomings of each prototype to be eliminated in order to come up with an optimum model step by step. The necessity of such testing could be justified considering this fact that usually it would be hard for designers to foresee real users' experience intuitively. Despite of all experienced methods in the field of architecture, urban design and landscape architecture to include inhabitants' opinions in the design process, always creative methods could also be applied by designers and developers based on specific characteristic or context of different projects to fulfill the goals of UCD more effectively. 


\section{Climate oriented design}

Environmental conditions and specifically climate have a substantial effect on the performance of many products including buildings and their energy consumption. 'Bio-climatic design' and 'climate adaptive design' are the terms particularly used in the field of architecture. Bioclimatic architecture has some main goals such as providing the users of building with comfortable and healthy conditions, reducing energy consumption of building and using natural energy and reducing energy from mechanical resources.

In his article, 'Climatic design of buildings using passive techniques', Rosenlund (2000) indicates that in developing countries less attention is paid to this method of design and the experiences from traditional architecture which was fairly adapted to the outdoor environment are usually not applied to modern techniques. Rosenlund also expresses that since modern construction provide users with possibilities for a better interior thermal comfort, compared with traditional construction which might have some shortages during a day or a year, many tend to ignore the passive methods of climatic adaptation of buildings.

Many factors can influence the energy performance of a building, from the building form with its impact on solar gain, wind protection and the associated surface area to volume ratio to construction techniques which can affect the quality of design implementation and selection of materials which has a direct impact on U-value of different elements, thermal mass, etc (Simm et al., 2011). On the other hand, there are HVAC systems which directly influence the energy consumption of a building. Energy efficiency of buildings is mainly achieved by minimizing the input of energy. In more technical systems of HVAC, the system is more dependent on complicated installations and energy supply and consequently more vulnerable while in passive methods, the system involves more human factors and requires more control by users and is consequently simpler and more reliable. However, due to changing lifestyles it is evidently not possible to rely only on purely traditional solutions and thus a combination of traditional knowledge and modern technology seems essential (Rosenlund, 2000).

What was stated by the 'Building Research Establishment' in the UK already in 1974, clarifies more the need for a climatic approach to architectural design of buildings:

It is not practicable to plan a building exclusively on economic, functional or formal grounds and expect a few minor adjustments to give a good indoor climate. Unless the design is fundamentally correct in all aspects, no specialist can make it function satisfactorily. Climate must be taken into account when deciding on the overall concept of a project, on the lay out and orientation of buildings, on the shape and character of structures, on the spaces to be enclosed and, last but by no means least, the spaces between buildings. In other words climate must be considered at the early design stage.

Basically in order to have a comprehensive analysis of the climatic conditions, major elements such as temperature, humidity, wind, precipitation, cloud cover, sunshine duration and 
solar radiation are studied from the regularly measured data. Furthermore, in a climatic design, topography, vegetation and Built environment are considered as site-related factors affecting the design strategies while shape and orientation of building, building fabric, fenestration and ventilation are the architectural design variables. For a proper thermal design, factors such as solar heat gain, conduction heat flow and ventilation heat flow should also be studied. Three main stages have been distinguished in climatic design; which are 'forward analysis', 'plan development' and 'element design' which compared with the traditional approach, can be more efficiently applied today by the help of powerful computer programs and modeling possibilities. Furthermore, with recent advances in material technology and development of new concepts such as climate adaptive skins (for more information see Hasselaar, 2006), there are now more opportunities to take building physics into account in the process of design and integrate modern techniques with traditional methods of climatic architecture.

\section{Energy efficient approaches to renovation of multi-family housing in Sweden}

\subsection{Background}

Recently, retrofitting of the housing stock has become one of the major issues for the housing sector in Sweden. The current physical problems with the large scale buildings of the million homes program, together with the fact that currently, Sweden has again faced a growing demand for housing, especially in large cities, and there are actually no plans for major demolition and redevelopment (Högberg et al., 2009), clarifies that retrofitting and refurbishment of this housing stock in the next few years will be inevitable. Furthermore, since buildings can play a major role in achieving energy saving goals, it can be seen as a great opportunity to carry out energy efficient measures in the renovation of the 'million homes program'. In their article, Höberg et al. mention this need for renovation as a window of opportunity which should not be missed. In order to comply with national climate goals for 2050, according to Femenías and Lindén (2011), since major refurbishment activities are carried out almost every 30-40 years or for some parts such as facades even every 60 years, the up coming construction projects in Sweden should be undertaken with the aim of at least 50 percent reduction in energy consumption.

\section{The million homes program}

Between 1965 and 1974 more than one million housing units were built in Sweden based on a political decision in order to handle the housing shortage in the country and low quality dwellings of the 1960s. In 1965 the Swedish parliament decided to implement this ambitious 
program with the goal of good housing for all (Femenías and van Hal, 2009) to make sure that everyone could have a home at a reasonable price. The governing Swedish social democratic party subsidised this development plan to stimulate construction. The program also included demolishment of a large proportion of inferior quality dwellings which finally resulted in an increase of 650,000 new apartments and houses in Sweden's housing stock. (Borgegård and Kemeny, 2004)

In order to fulfil the goal in such a short period of time and due to shortage of labour, prefabricated construction methods were widely applied. Since the constructions completed, many have criticized the program and complained about its aftermath. Some believe that it has created a lot of ugly concrete buildings which have destroyed the cityscape. The program is now popularly associated with the so called 'concrete suburbs', i.e. dull, grey, low-status suburbs made mainly out of concrete slabs.

This miscalculation of the early future need for housing or the ambitious plan to have a housing surplus instead of shortage caused Sweden to have considerable vacant apartments after million homes program areas were built. Consequently in some cases housing companies decided to demolish a small proportion of their housing stock which was costly to be maintained.

Today, almost four decades after this construction project, many of these buildings suffer from old and exhausted installations. For instance in some cases there is a high risk of damage caused by leakage from water and sewage pipes which are not in a good condition or in other cases mechanical or electrical systems do not function properly. Furthermore, new and untested construction techniques and materials as well as a too fast and sloppy work performance have led to other damages than those related to normal aging (Högberg et al., 2009, p. 1353). Major problems with these buildings are damaged balconies, facades and roofs, substantial heat losses due to thermal bridges in buildings' envelopes, poor insulation of exterior walls, no heat recovery in the ventilation systems and units which are not well air tight.

\subsection{Case studies}

For this study two cases have been selected which are both well-known demonstration projects of multi-family housing renovation in Sweden. Gårdsten in Gothenburg and Brogården in Alingsås have been renovated with the main focus on the energy performance of the building but with two different approaches to energy efficiency.

\subsubsection{Solar Houses, Gårdsten, Göteborg}

\subsubsection{Situation/Background}

This project is located in Gårdsten, a suburban area $10 \mathrm{~km}$ to the north east of Gothenburg, which was originally built in the early 1970s (1969-1972) as part of the Million homes pro- 
gram and comprised a whole number of 2700 apartments(Figure 7). Almost from the beginning, lack of maintenance and local services, health problems, poor public transportation, unemployment, high rate of vandalism and crime and consequently social segregation and insecurity made Gårdsten a stigmatized problematic area in the city. All these, together with technical issues with the buildings and the unpleasant gray, brutal appearance of the environment had caused considerable vacant flats in the area (almost 30\%). In 1996 Gårdsten was one of the most deteriorated living areas in Sweden (Femenías et al., 2011) when the city of Gothenburg decided to make a major change in this district. (Figure $8 \& 9$ )

\subsubsection{Gårdstensbostäder}

The municipal housing company Gårdstensbostäder was established in 1997 with the explicit task of regenerating and developing the district of Gårdsten (Femenías et al., 2011) and purchased approximately 2000 apartments, previously owned by 'Bostad AB Poseidon' and 'Göteborg Stads Bostadsaktiebolag'. Currently this company owns all the rental flats in the district after it acquired the other 700 apartments in North Gårdsten.

\subsubsection{Goals and objectives}

The first action to regenerate the area was to make a physical refurbishment in order to provide the tenants with better living standards and the aim was to revitalize the social structure to create a more attractive living environment. The goals would not be fulfilled without active participation of the tenants in the process and an effort to integrate a community of which a large proportion was immigrants. Furthermore, to reduce the energy costs and use of renewable energy in order to make the development more sustainable, a renewable energy design was considered to be integrated to the renovation project.

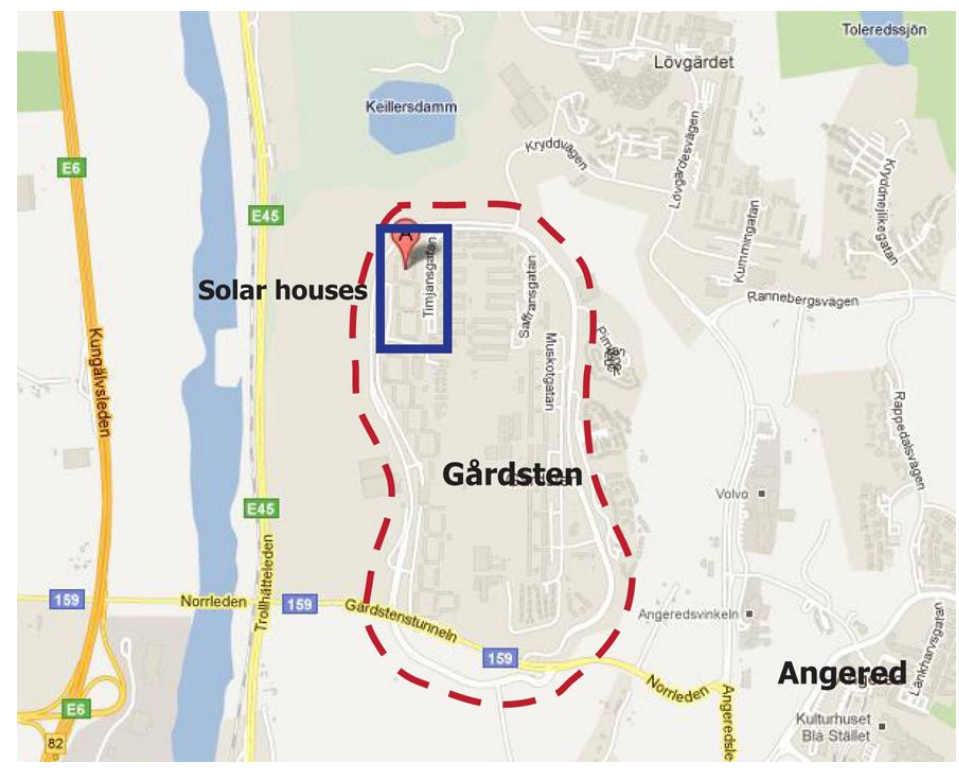

Figure 7: Situation of Solar houses in Gårdsten 


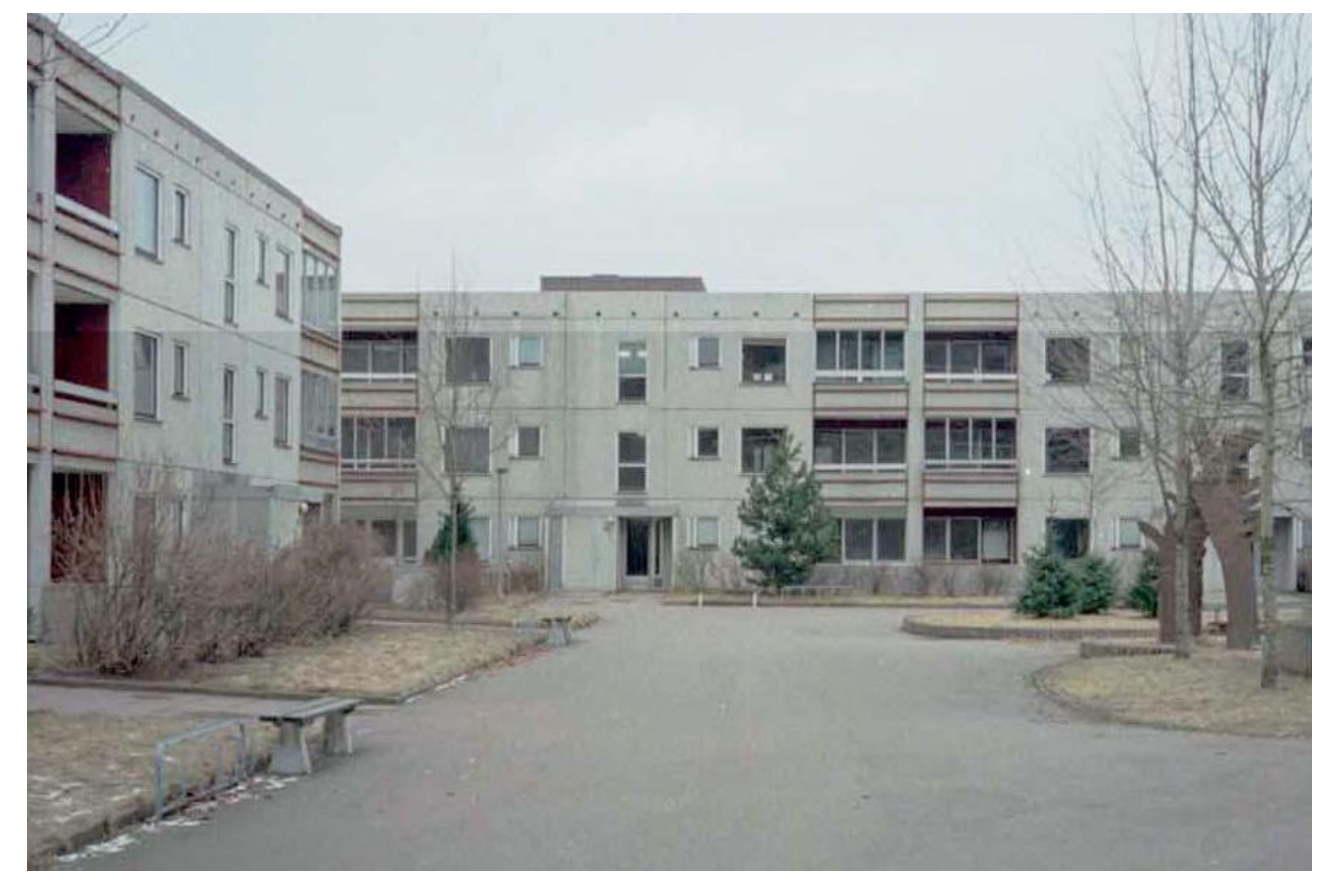

Figure 8: Unpleasant gray façades of buildings, Gårdsten before renovation

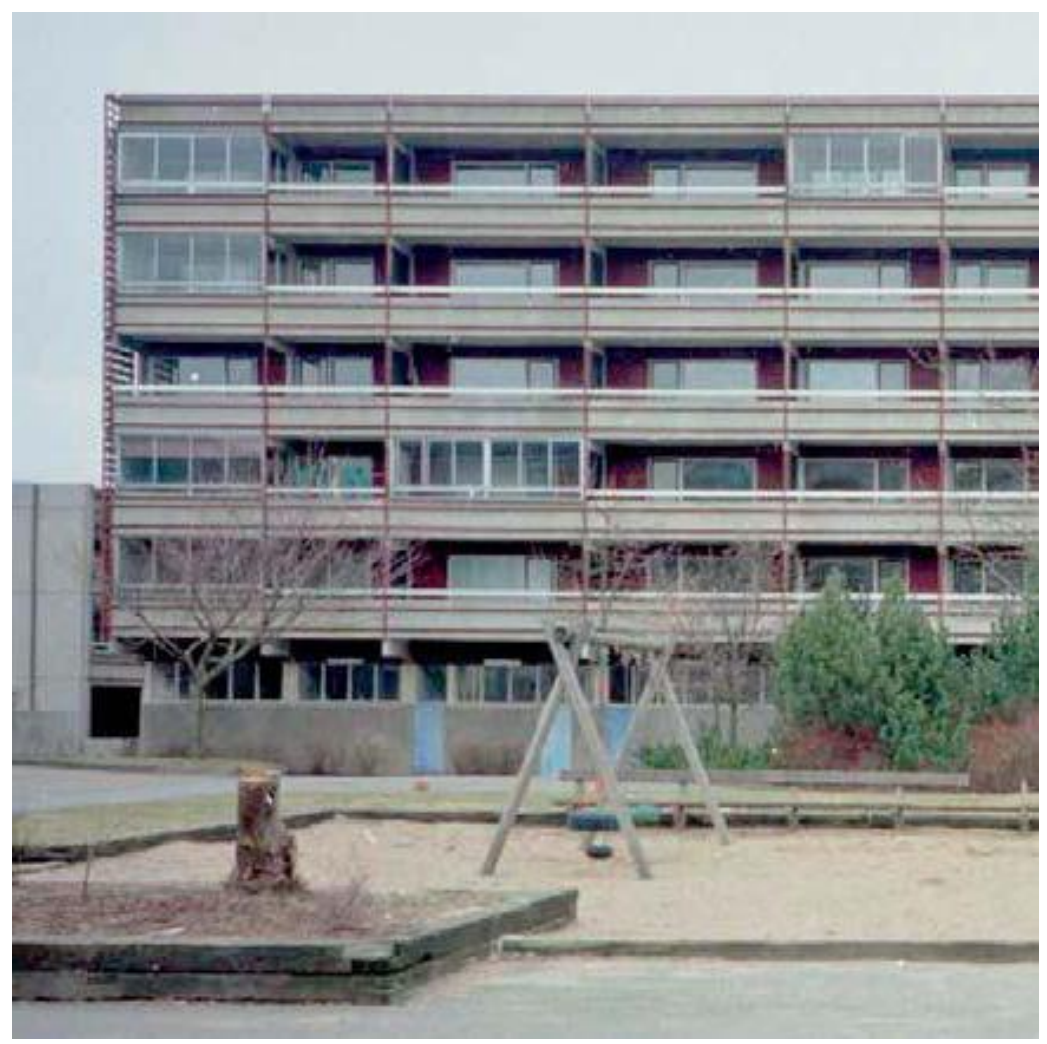

Figure 9: Poor quality of outdoor environment, Gårdsten before renovation 


\subsubsection{Project description}

The so called 'Solhus1' (Solar houses1) is the renovation of 255 out of 1200 apartments in West Gårdsten, as a demonstration project, in collaboration with 'Christer Nordström Arkitektkontor $A B^{\prime}$ ' as the architect and 'Professor Jan-Olof Dalenbäck' a researcher at Chalmers University of Technology as the HVAC consultant. The project was started at the time for the call for targeted projects for the THERMIE program in 1996, and carried out with financial support from EC (SHINE - BU/1051/96). The renovation project started in early 1998 and was finalized in 2001 when the first block was already completed, in the early 2000.

This first phase of the project comprised retrofitting and refurbishment of 10 buildings ( 3 high-rise and 7 low-rise) with 18720 square meters of living area, forming 3 apartment blocks, around 3 central courtyards. Each U-Shaped block consists of one 6-story building (5 story on pilotis) to the south and two 3-story buildings to the east and west except the last block to the north which is bounded with an extra 3-story building to the north (Figure 10).

The three 6-story buildings facing south/north have external staircases with flat entrances in long balconies to the north front of the buildings and the seven 3-story buildings have conventional internal staircases. All the buildings which have flat roofs have been constructed by prefabricated concrete elements. In Each block, electricity, heat and water are served to all the buildings from the sub-station which is in the 6-story building. The buildings are provided with heat from district heating system.

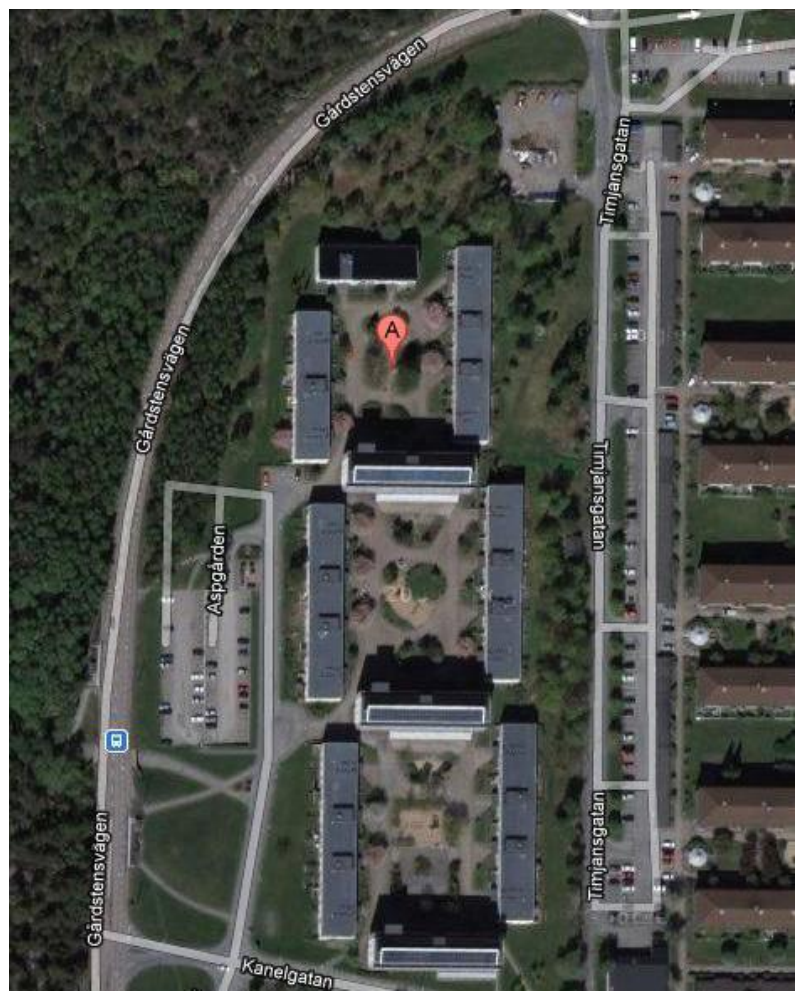

Figure 10: First phase of solar houses, 10 buildings in three blocks 


\subsubsection{5. $\quad$ Energy Efficiency Measures}

Although all the buildings have been renovated as a single project, some different concepts for energy efficiency have been wisely chosen for high-rise and low-rise buildings based on their specific conditions and opportunities. The Changes are more visible in 6 story buildings but some of these measures benefit all the units in the whole block.

The original flat roofs have been covered by extra insulation on top and a shed roof facing south with integrated solar collectors for preheating domestic hot water was added on top of each high-rise building. In each block, storage tanks have been placed in the basement of 6story building and preheated water (heated almost 35\% by solar energy) is stored there to be distributed to all the apartments and the common laundry in the block. The supplementary heat is provided through district heating system.

Furthermore, the previous open balconies to the south have been repaired and enclosed with glazed panels (Figure 11). The apartments are supplied with fresh air preheated by sunlight through these glazed balconies. Fresh air enters the living rooms and bed rooms adjacent to these balconies through 'brush sealing' air inlets designed in the windows and balcony doors which would reduce dust and pollen. The exhaust air is directed out from the existing exhaust system in kitchens and bathrooms on the northern part of the flats. 'The exhaust ventilation is operated with a minimum flow dependent on outdoor temperature and the kitchens are equipped with separate kitchen fans with carbon filters' (Dalenbäck, 2007). (Figure 12)

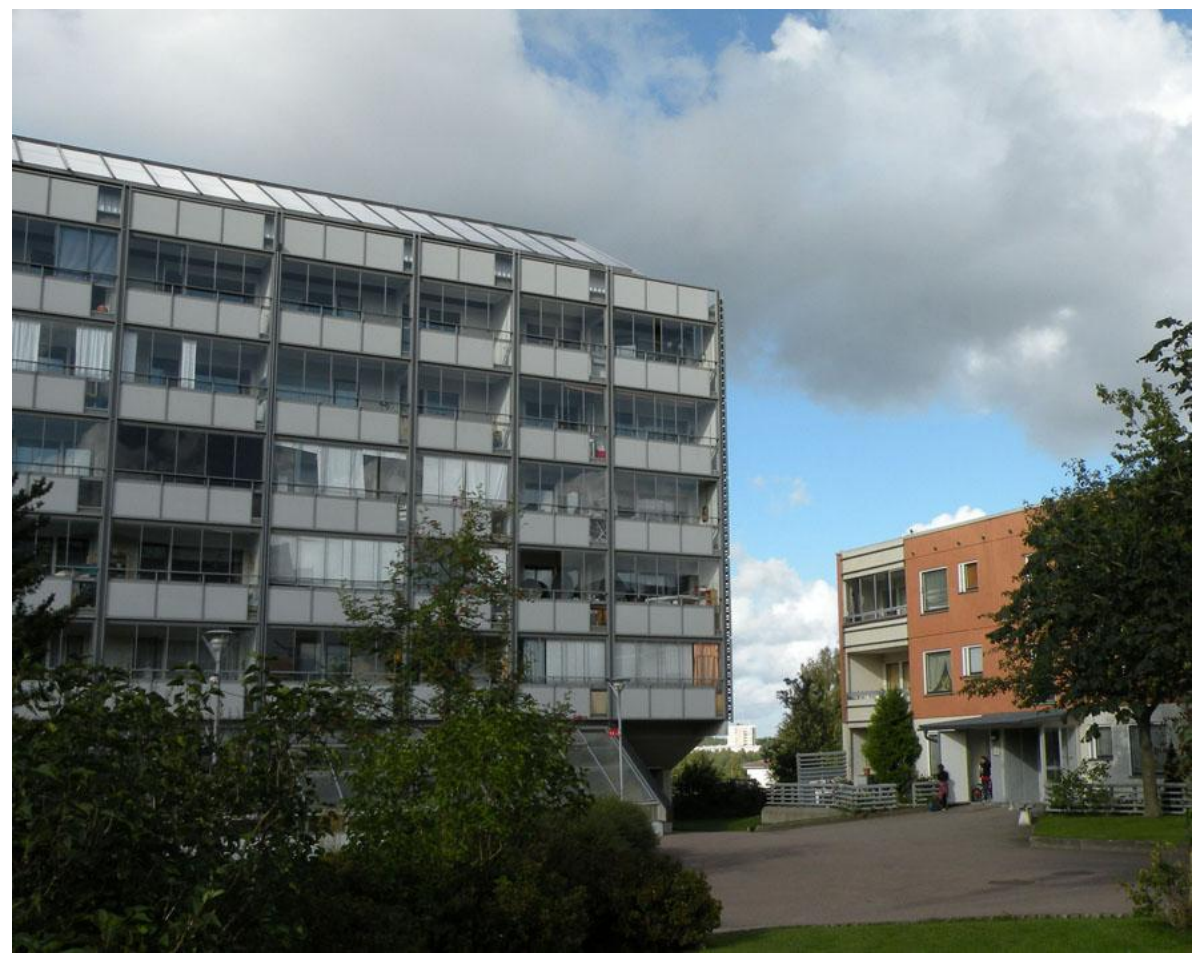

Figure 11: Enclosing the previous balconies of high-rises in Gårdsten with glazed panels 


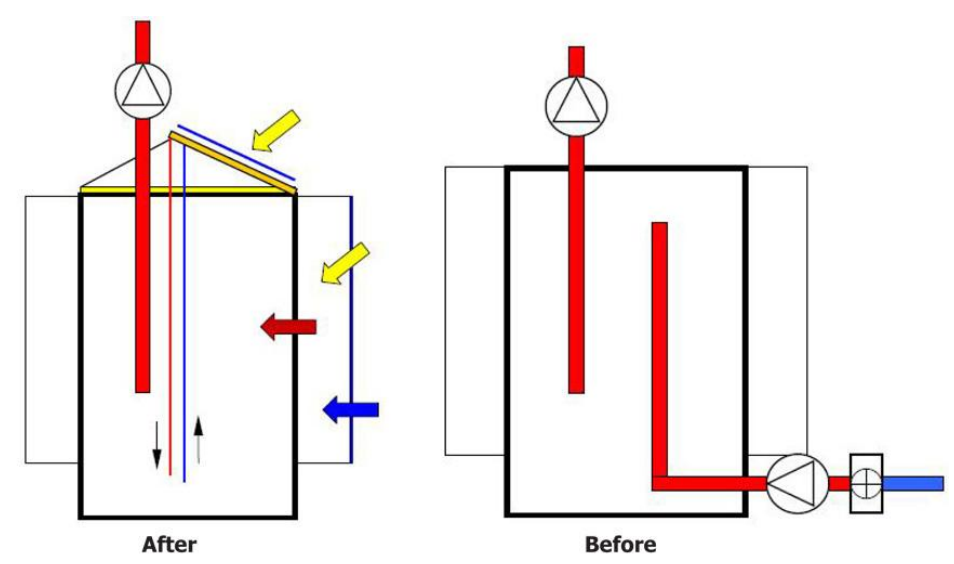

Figure 12: Ventilation system of high-rises in Gårdsten before and after renovation

On the other hand the glazed panels protect the south front of the building from the prevailing winds and could be moved to one side in order to open up the balcony in warm days. Despite of low investment incentives for insulation of all external walls due to low energy costs, the gables in the high-rise buildings were insulated and got new cladding because of problems with water penetration.

Existing laundry rooms, located in the basement of the high-rise buildings were replaced with new laundry rooms, designed in the ground floor of these buildings. The new laundries were equipped with energy efficient washing and drying machines, connected to the domestic hot water system in the basements to save electricity for water temperatures below $50^{\circ} \mathrm{C}$. Moreover, communal greenhouses have been built on the ground level of these buildings, adjacent to the new laundry rooms along more than half the length of the building to the south. These greenhouses not only provide the inhabitants with meeting places for social interaction while growing vegetables, flowers etc. (Figure 13), but also protect the laundry rooms from cold outdoor weather and prevent cold bridges in the first floor slabs (Figure 14). They would also protect the courtyards from strong winds and provide a better comfort even in the outdoor space (Figure 15).

In low-rise buildings the existing ventilation systems were equipped with a heat recovery installation and the flat roofs were covered by external thermal insulation (Figure 16). In the ground level of these buildings, the floor slabs were insulated at their edges to reduce thermal conduction in the slabs. The low-rise building facing south, in the last block to the north, has a unique design in this project. The external walls to the east, north and west of this building have been covered with an extra layer of thermal insulation and a cavity has been created between the original walls and this new layer. These walls are not only protected from outdoor cold weather by the insulation layer but also warmed up by circulation of heated air in this gap and the air is heated through solar collectors vertically installed and integrated to the southern façade of this building. (Figure 17\&18) 


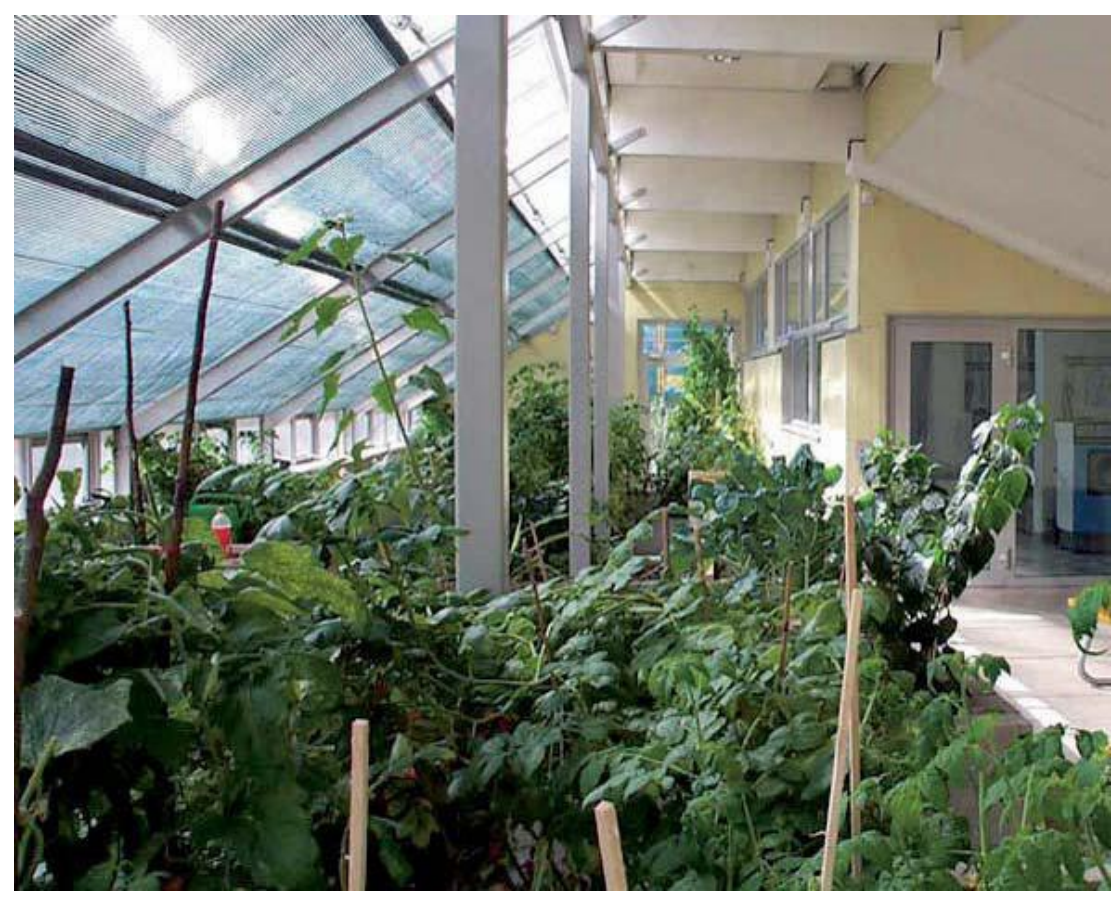

Figure 13: Greenhouses as communal spaces in the ground floor of high-rises, solar houses I

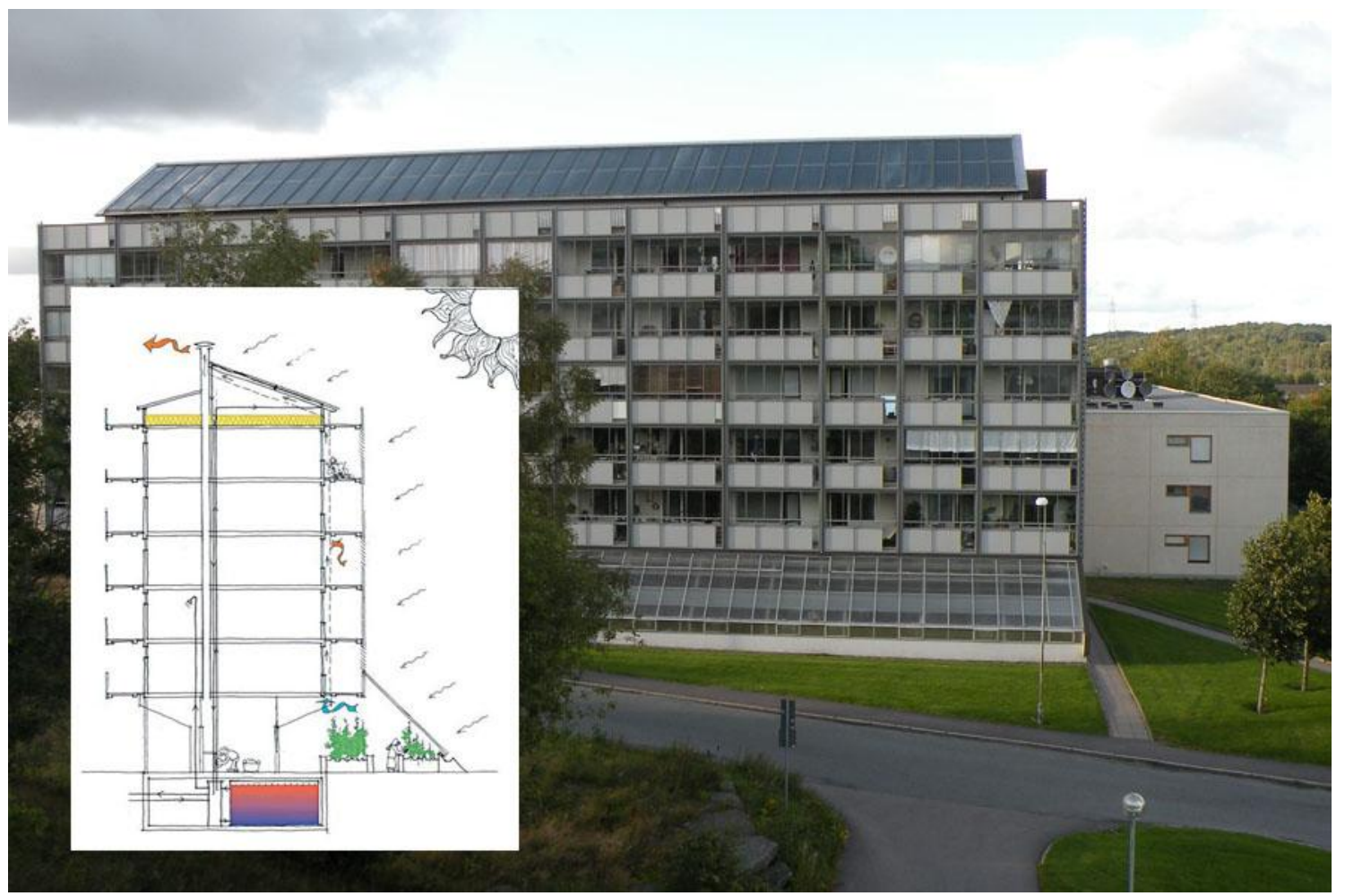

Figure 14: Greenhouses adjacent to laundry rooms in the ground floor of high-rises, solar houses I 


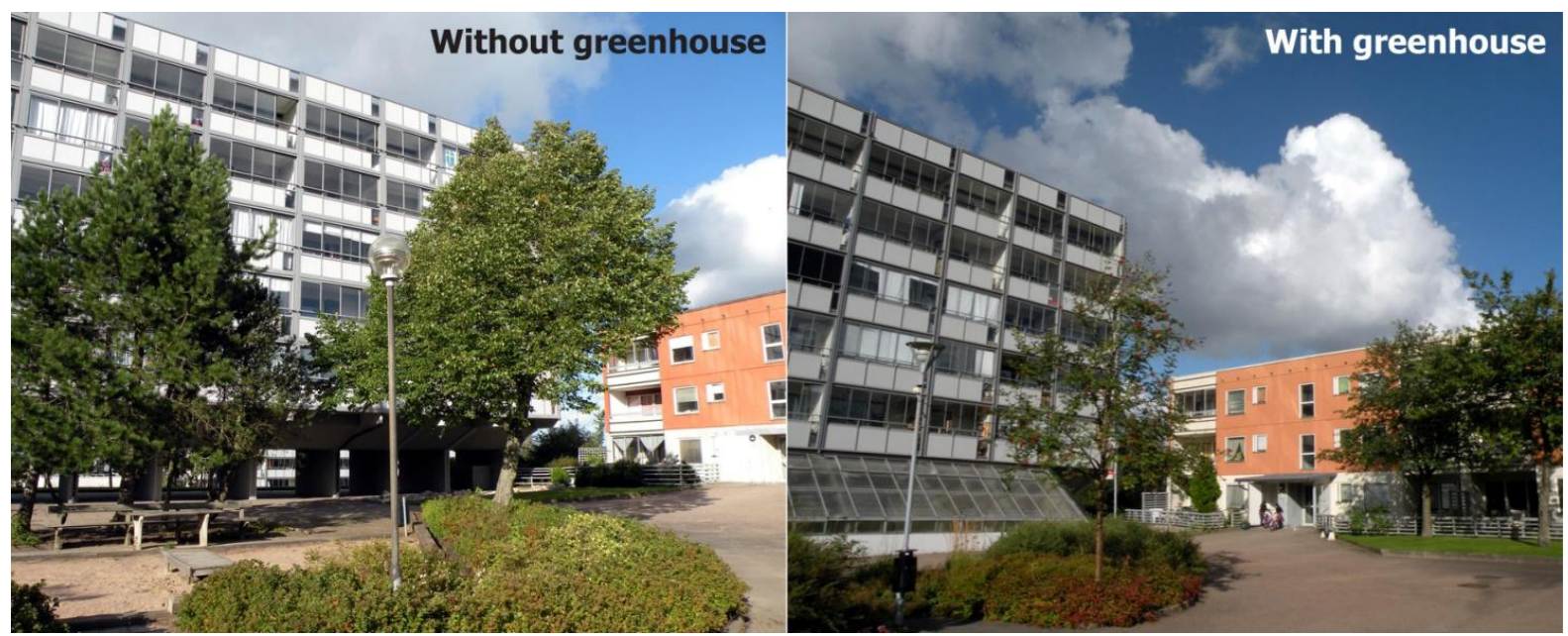

Figure 15: Courtyards being protected against strong winds by greenhouses in solar houses I

In all buildings the inner window panes of the existing double glazed windows have been replaced with new low-emission panes, and in case of major damage the entire window has been changed. All apartments have been equipped with energy efficient household appliances such as refrigerators and stoves and low-flow taps and toilets. In staircases the electricity consumption is controlled in by installing occupancy sensors for lighting system.

Furthermore, all households have been provided with individual metering systems for water, electricity and space heating in their flats which are all connected to a central control system for supervision, and each household will receive individual utility bills. For space heating the default average temperature inside the flat is assumed to be $21^{\circ} \mathrm{C}$. If the tenants prefer higher or lower temperatures their rent would be affected accordingly. Each greenhouse is equipped with a compost machine which turns the households' waste into soil suitable for planting.

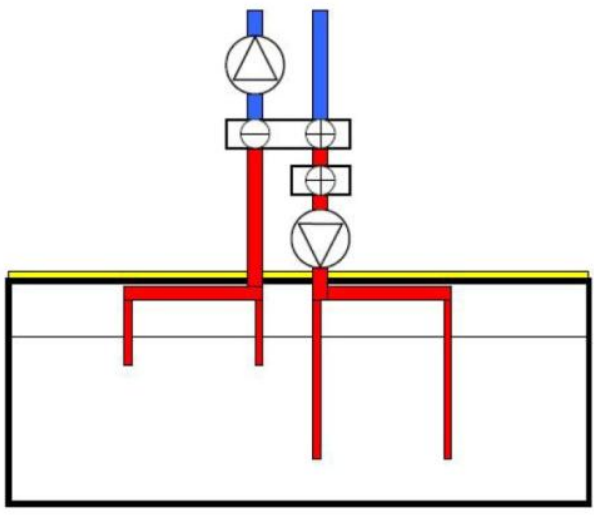

After

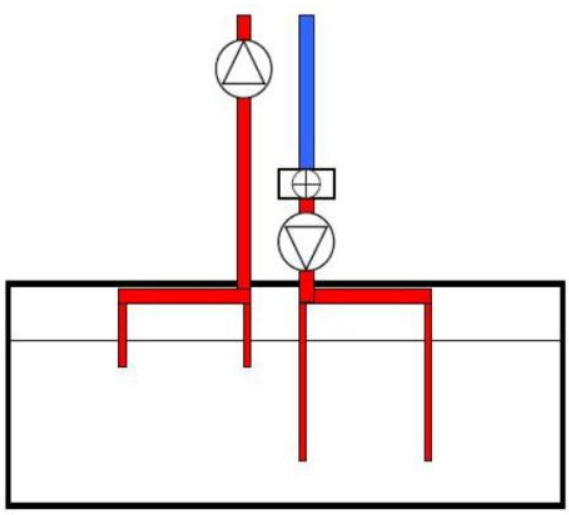

Before

Figure 16: Ventilation system of low-rises in Gårdsten before and after renovation 


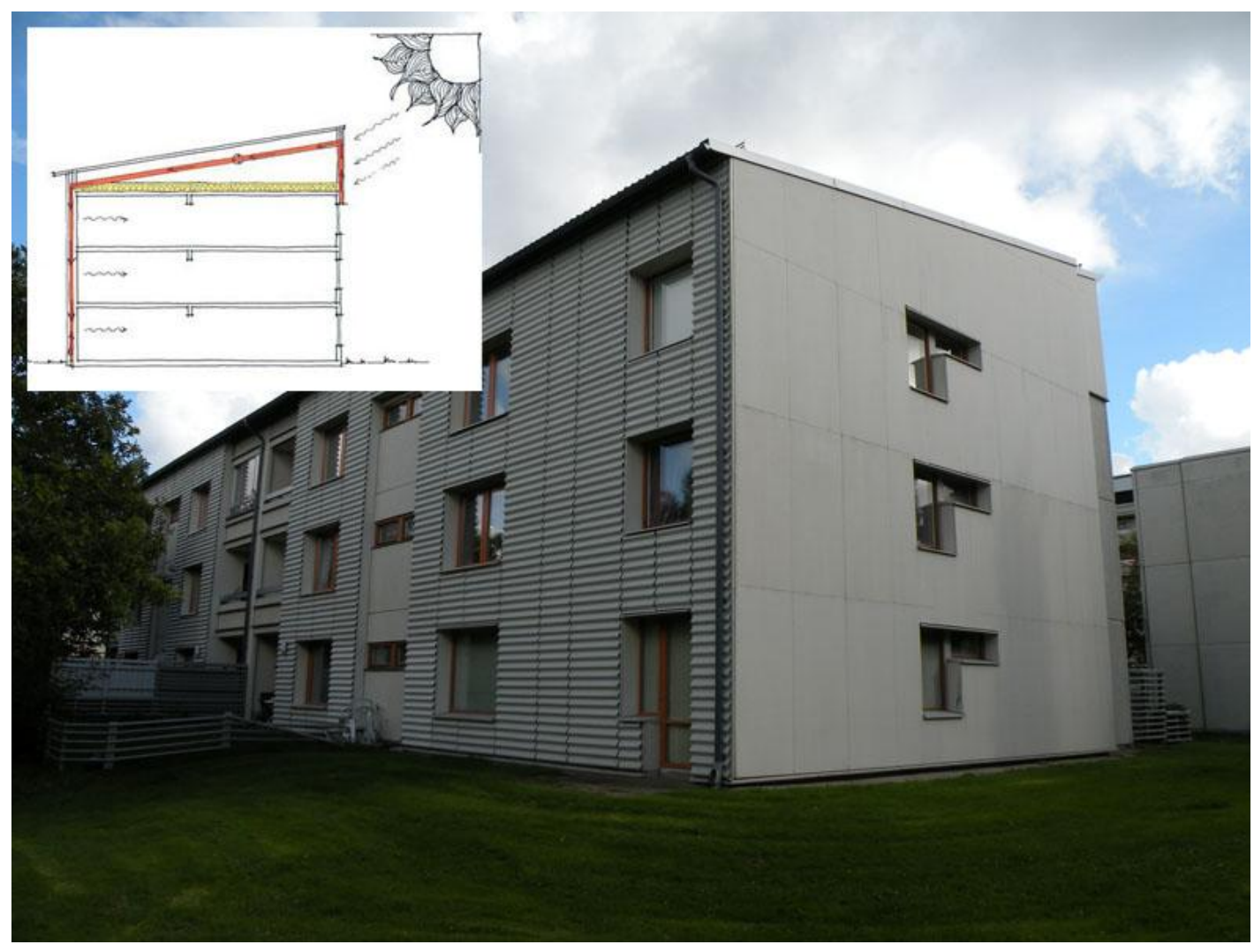

Figure 17: Heating system of exterior walls in the low-rise facing south, solar houses I

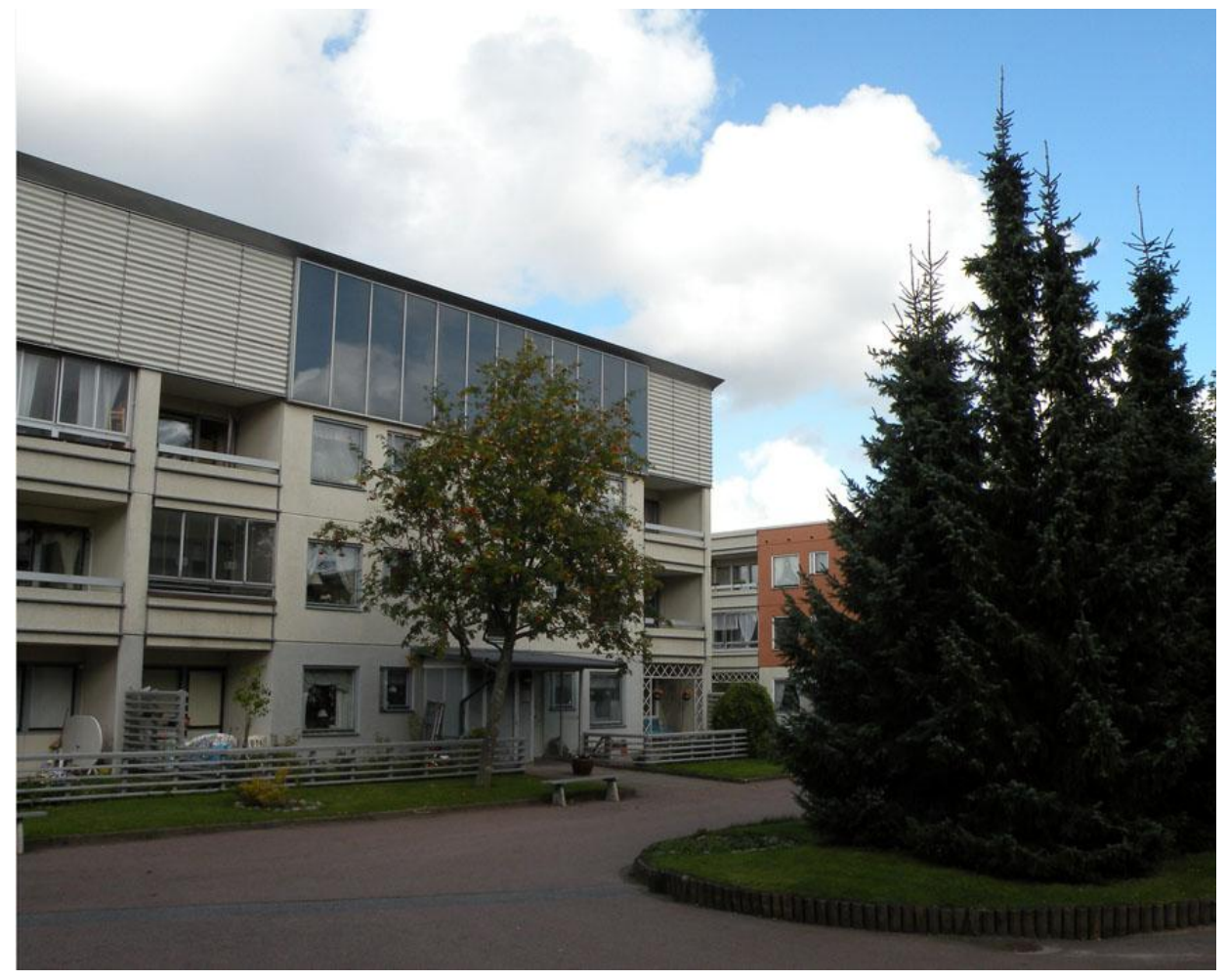

Figure 18: Solar panels installed on the southern facade of the low-rise, solar houses I 


\subsubsection{Passive houses, Brogården, Alingsås}

\subsubsection{Situation/Background}

The housing area of Brogården is located in Alingsås, a small town $47 \mathrm{~km}$ outside Gothenburg. This area which consisted of 299 rental apartments in sixteen 3-story buildings was originally constructed in the early 1970s (1971-1973) as part of the 'million homes program' (Figure 19\&20).

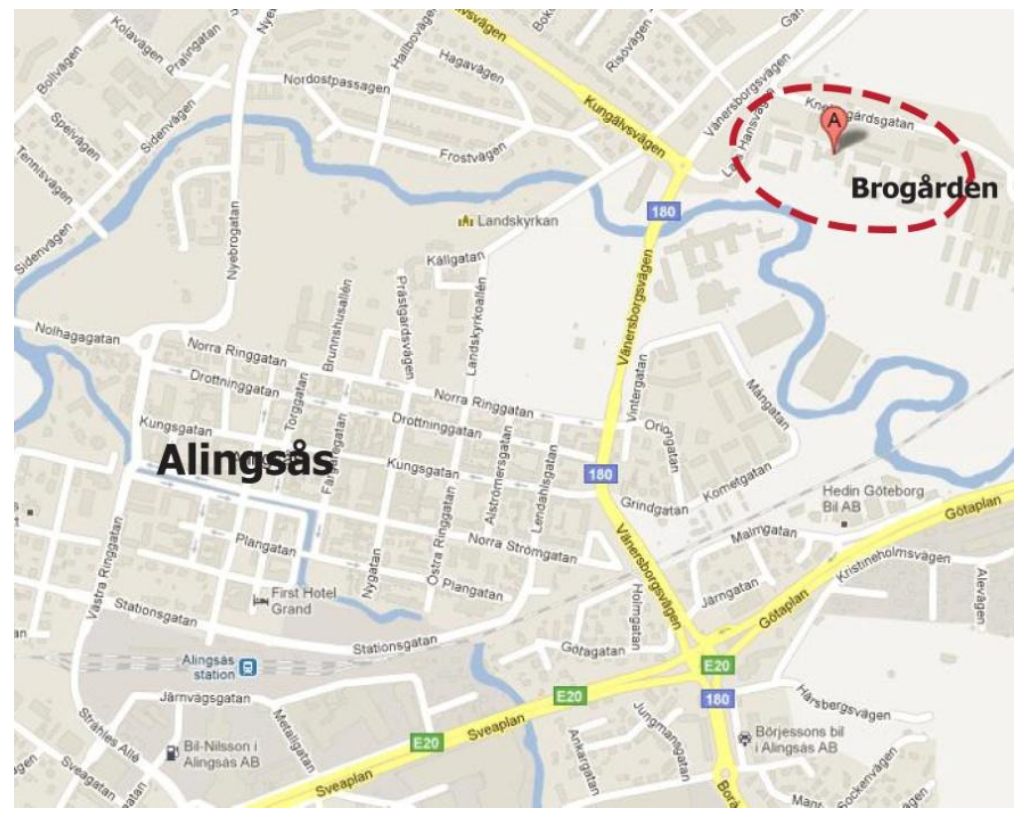

Figure 19: Situation of Brogården in Alingsås

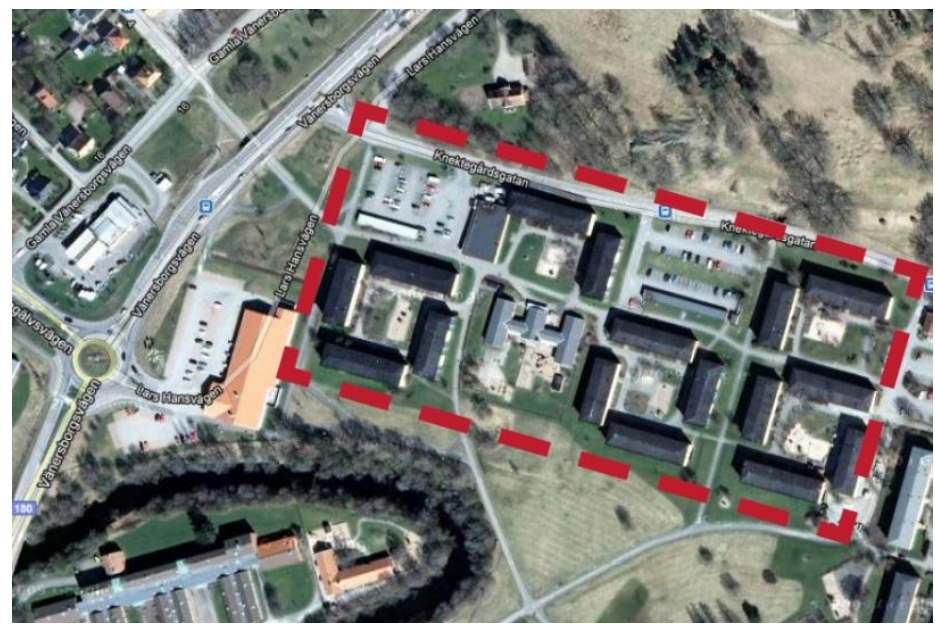

Figure 20: Building blocks in Brogården 
The apartments are owned and managed by Alingsåshem which is a public housing company in Alingsås municipality. Although this popular residential area, with no vacant flats, has benefited continuous maintenance activities and even renovation of some parts during the years, it was still in need of major retrofitting in 2005 when the planning process started (Figure 21). As Janson explains in her paper, the inhabitants had not been satisfied with the indoor climate and draft inside their apartments. The brick facades, which had been changed earlier, were again in a poor situation and penetration of acid rains and frost in the materials had caused serious cracks in them (Figure 22). Moreover, the flats had not been easily accessible for disabled and elderly people since for example none of the buildings had elevators.

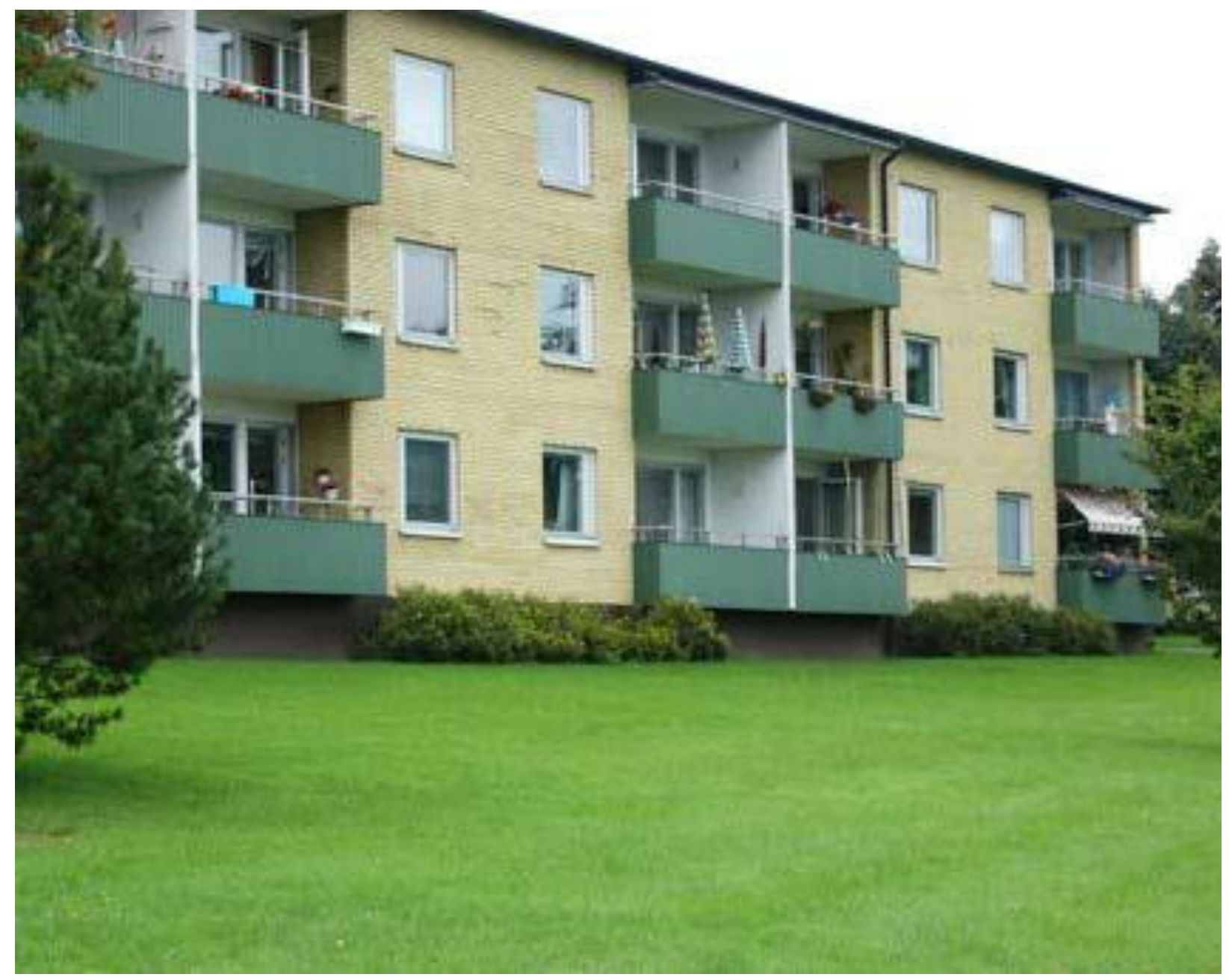

Figure 21: Pleasant appearance of the buildings and the environment in Brogården before renovation 


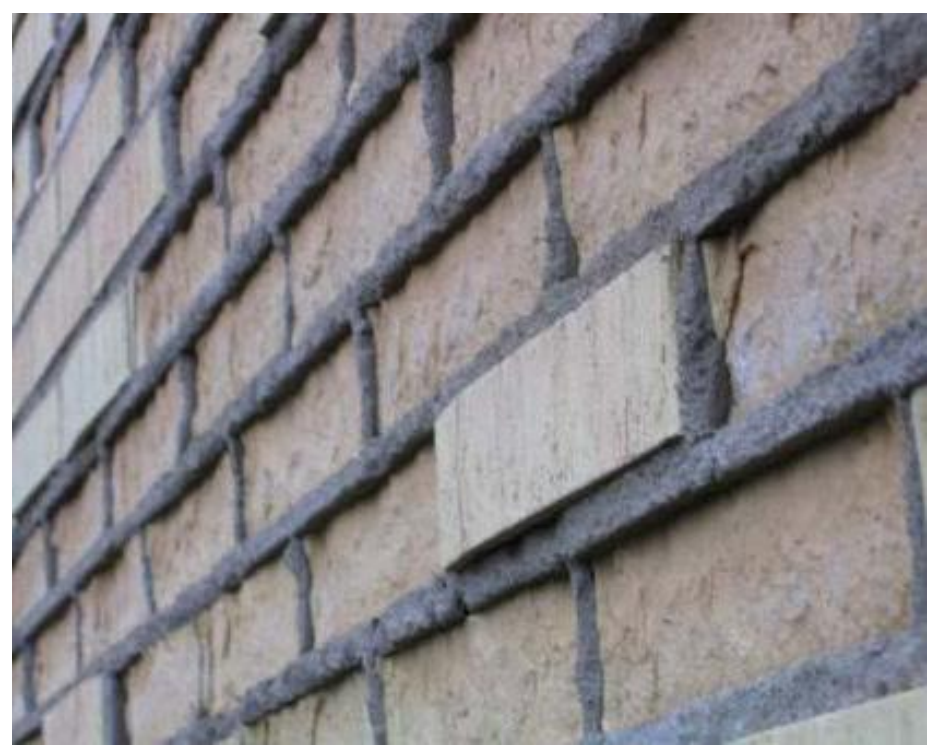

Figure 22: Poor condition of brick facades in Brogården before renovation

\subsubsection{Passive house concept}

As already mentioned, the buildings in Brogården had been partly renovated earlier and even measures regarding energy efficiency had been applied; including additional insulation for the roofs and replacing the outer pane of the double-glazed windows to a double pane lowenergy construction and providing triple glazed windows. However, these measures had not been enough to reduce the energy consumption to an acceptable level. Furthermore, in the renovation of its other dwellings, the housing company experienced that after the renovation the tenants still suffered from uneven indoor temperatures and drafts. Since in this project both the facades and the exterior walls had to be rebuilt due to their poor technical conditions, this was considered as a great opportunity to make a radical change in the construction system and provide more insulation for the building envelope. These motivations together with the focus of the housing company on saving energy and the environment resulted in applying the concept of passive house technology in Brogården renovation.

\subsubsection{Project description}

Alingsåshem started the construction process in collaboration with 'EFEM Arkitektkontor $\mathrm{AB}^{\prime}$ ' as the architect and 'Skanska $\mathrm{AB}^{\prime}$ as the main contractor in March 2008 with renovation of one of the buildings, consisting 18 apartments, as a demonstration project. The building has two separate entrances; each provides access to 9 apartments in 3 stories. (Figure 23)

All the buildings have a prefabricated load bearing concrete structure. The ground construction is originally a non-insulated concrete slab. The gables are made of concrete and other 
external walls have a wooden construction, with $100 \mathrm{~mm}$ of insulation, but the façade material is mainly brick. All the ceilings are of prefabricated concrete elements and the last ceiling in the original construction was insulated on the attic floor by $180 \mathrm{~mm}$ of mineral wool and a layer of cellulose insulation.

Before the renovation the apartments were heated by radiators connected to district heating system. Domestic hot water and household electricity were also included in the rents. The flats were supplied with fresh air through air inlets, built in the window frames, and each 9 apartments, around a staircase, had a common exhaust fan connected to exhaust ventilators in each kitchen and bathroom without heat recovery.

This was the first time in Sweden that a building was being renovated with passive house techniques and therefore it was quite necessary to educate everyone who was involved in the project in order to clarify the common goals and issues of this method of construction before it was started. So the first day in the process was a session full of information and discussion and almost all contractors and workers were invited. Furthermore, all experiences in the first building were documented and the process was evaluated by the consultants and the contractors to be applied in the renovation of other buildings.

The planning for the second phase of the project started in August 2008 which consisted of renovation of two other buildings in the area and the whole project is to be completed in 2013.

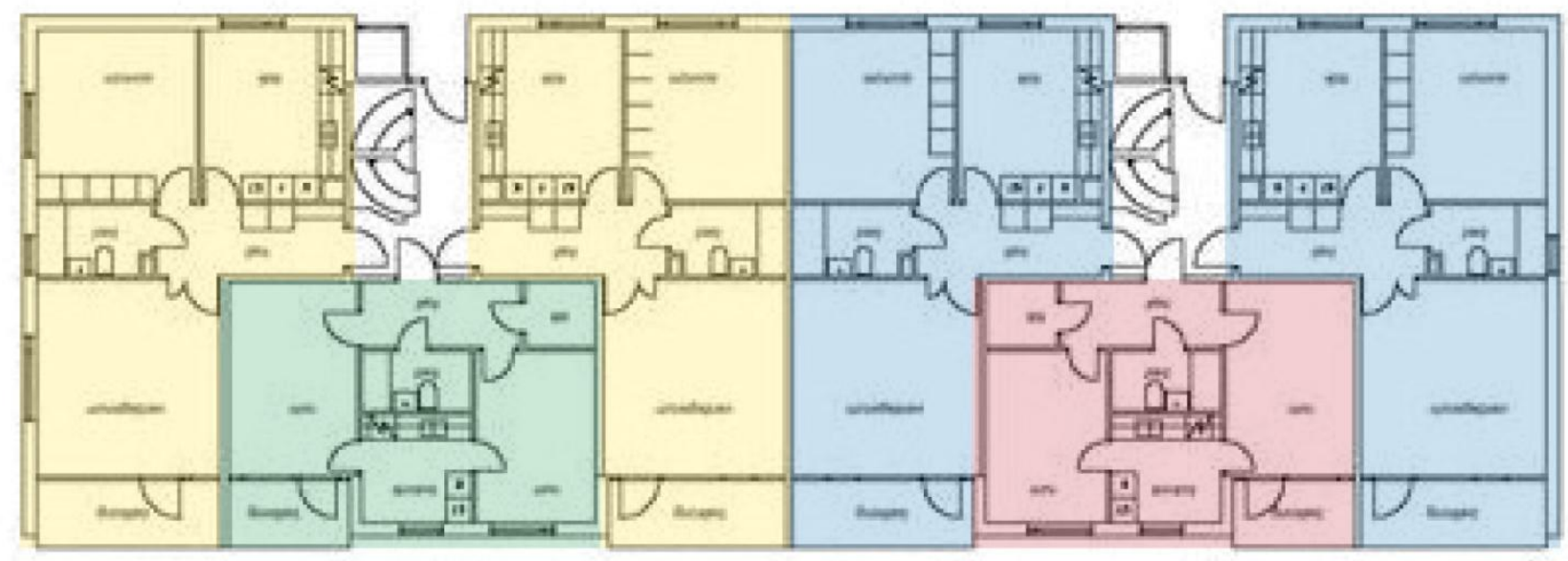

Figure 23: Typical lay out of apartment units in the buildings in Brogården 


\subsubsection{Energy Efficiency Measures}

The main idea behind passive house concept is making heat losses as less as possible. This technology involves sufficient insulation for building envelope as well as making it as air tight as possible. In such a system not much energy is needed for space heating and the air inside the building would be sufficiently warmed by the heat from occupants' body and the energy emitted from activities, lamps, hot water and household appliances already existing in the space. In order to provide fresh air in such airtight spaces, the buildings are equipped with heat recovery ventilation systems of high efficiency.

In Brogården the external shell of the building was highly insulated; the ground slab (except in the bathrooms) has been insulated with $60 \mathrm{~mm}$ of EPS (expanded polystyrene) on top of a moisture proof membrane and under the floor finishing which is parquet or plastic flooring. This slab has been also insulated with $140 \mathrm{~mm}$ of EPS (Skanska, 2009) from outside to avoid the thermal bridges. (Figure 24)

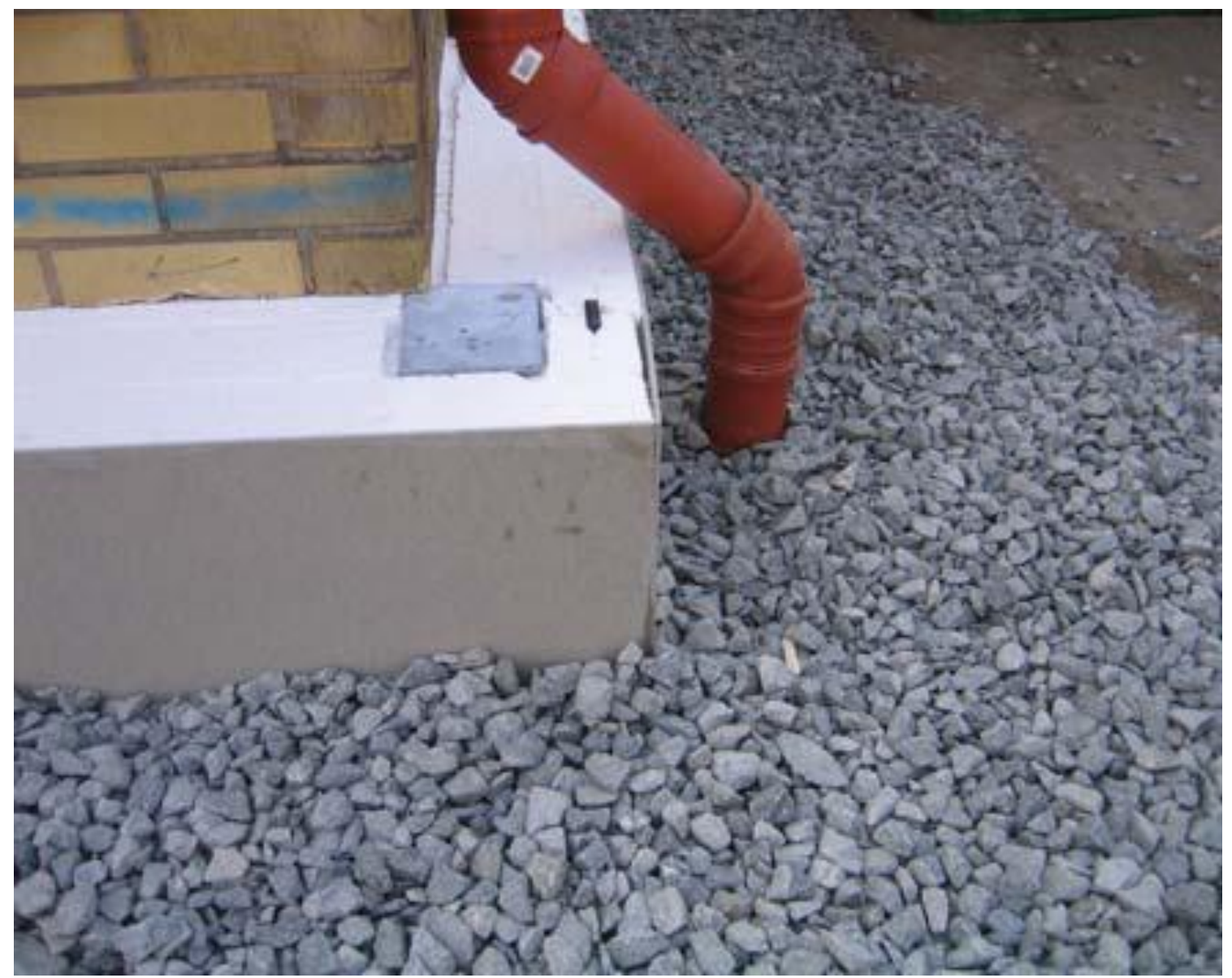

Figure 24: Insulation of the ground slabs in Brogården buildings 
Initially it had been decided to keep the wooden construction of the exterior long side walls, but as they were in a very poor condition they were completely replaced with newly built walls. These new exterior walls have a steel structure with layers of mineral wool, EPS and insulating board (approximately $440 \mathrm{~mm}$ ). There is also a plastic foil inside the walls which is protected by one of the insulation layers. A thin layer of façade, made of natural clay freezeresistant bricks, has been installed to steel profiles outside the wall which makes the wall to have a total thickness of $520 \mathrm{~mm}$. As no mortar has been used to connect the bricks to each other or to the wall, they could be easily replaced in case of damage. (Figure 25)

Both layers of mineral wool and cellulose insulation on the attic floor were removed and replaced with 400-550 mm of new loose wool insulation (Skanska, 2009).

All windows and entrance doors were replaced with xenon gas-filled triple glazed thermo windows and highly insulated doors respectively. U-value of different elements of the construction is presented in the following table.

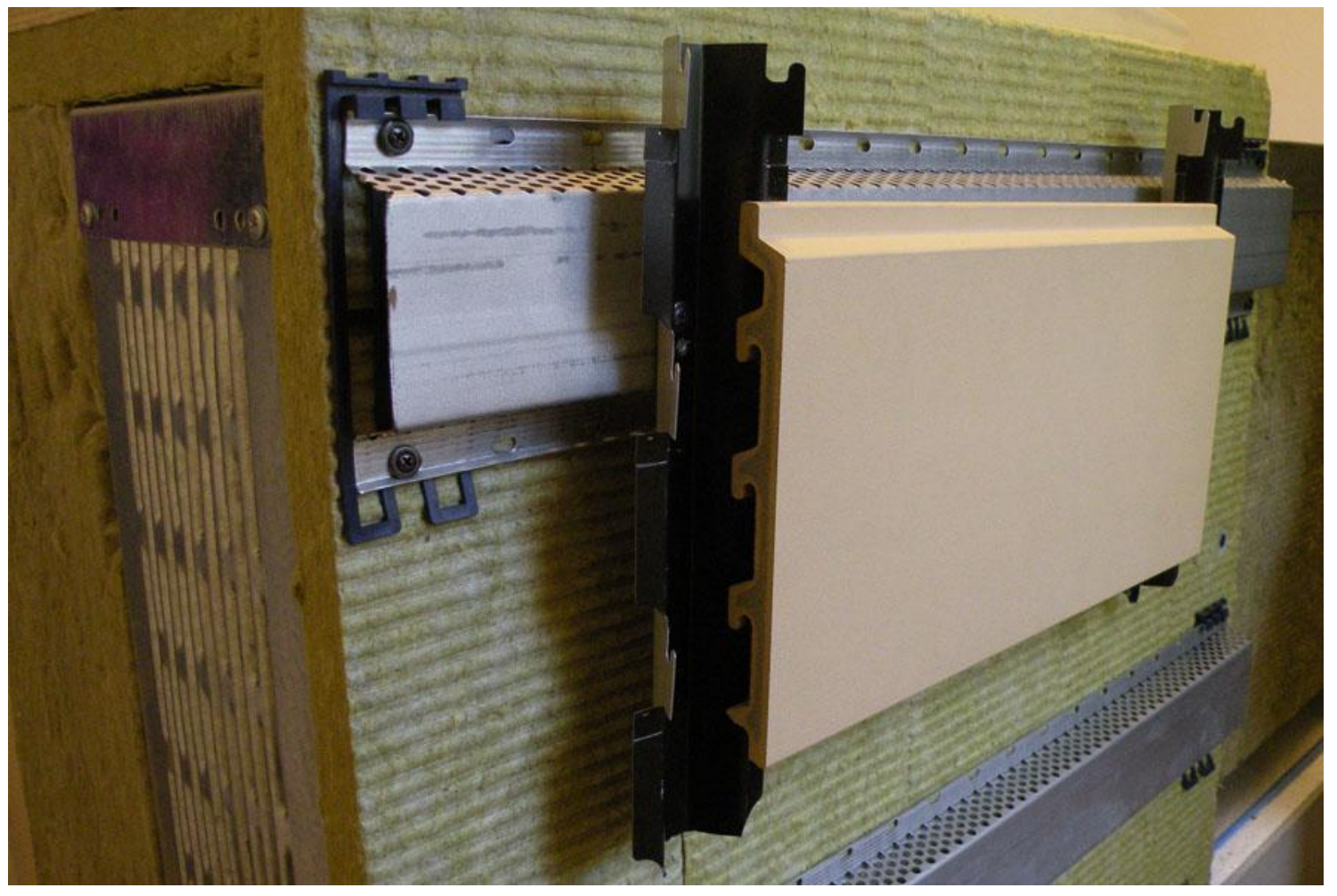

Figure 25: Installation of the new facade tiles in Brogården renovation 


\begin{tabular}{|l|c|c|c|}
\hline Building elements & $\begin{array}{l}\text { U-value before } \\
\text { renovation }\left(\mathbf{W} / \mathbf{m}^{2}{ }^{\circ} \mathbf{K}\right)\end{array}$ & $\begin{array}{l}\text { Building } \\
\text { in Sweden }\left(\mathbf{W} / \mathbf{m}^{2}{ }^{\circ} \mathbf{K}\right)\end{array}$ & $\begin{array}{l}\text { U-value after } \\
\text { renovation }\left(\mathbf{W} / \mathbf{m}^{2} \mathbf{K}\right)\end{array}$ \\
\hline Ground construction & $0.40-0.44$ & 0.15 & $0.20-0.26$ \\
\hline Exterior walls & $0.3-0.32$ & 0.22 & $0.095-0.11$ \\
\hline Attic floor & 0.22 & 0.13 & 0.10 \\
\hline Entrance doors & 2.70 & 1.20 & 0.75 \\
\hline Windows & $2.00-2.80$ & 1.20 & 0.85 \\
\hline
\end{tabular}

Table 1: A comparison of the U-value of building elements in Brogården

The existing recessed balconies which made substantial thermal bridges in the external walls and made low floor temperature for the adjacent rooms were enclosed as part of the apartment interior space and new balconies were built, standing on a separate structure and mounted on the outside of the façade. (Figure 26)

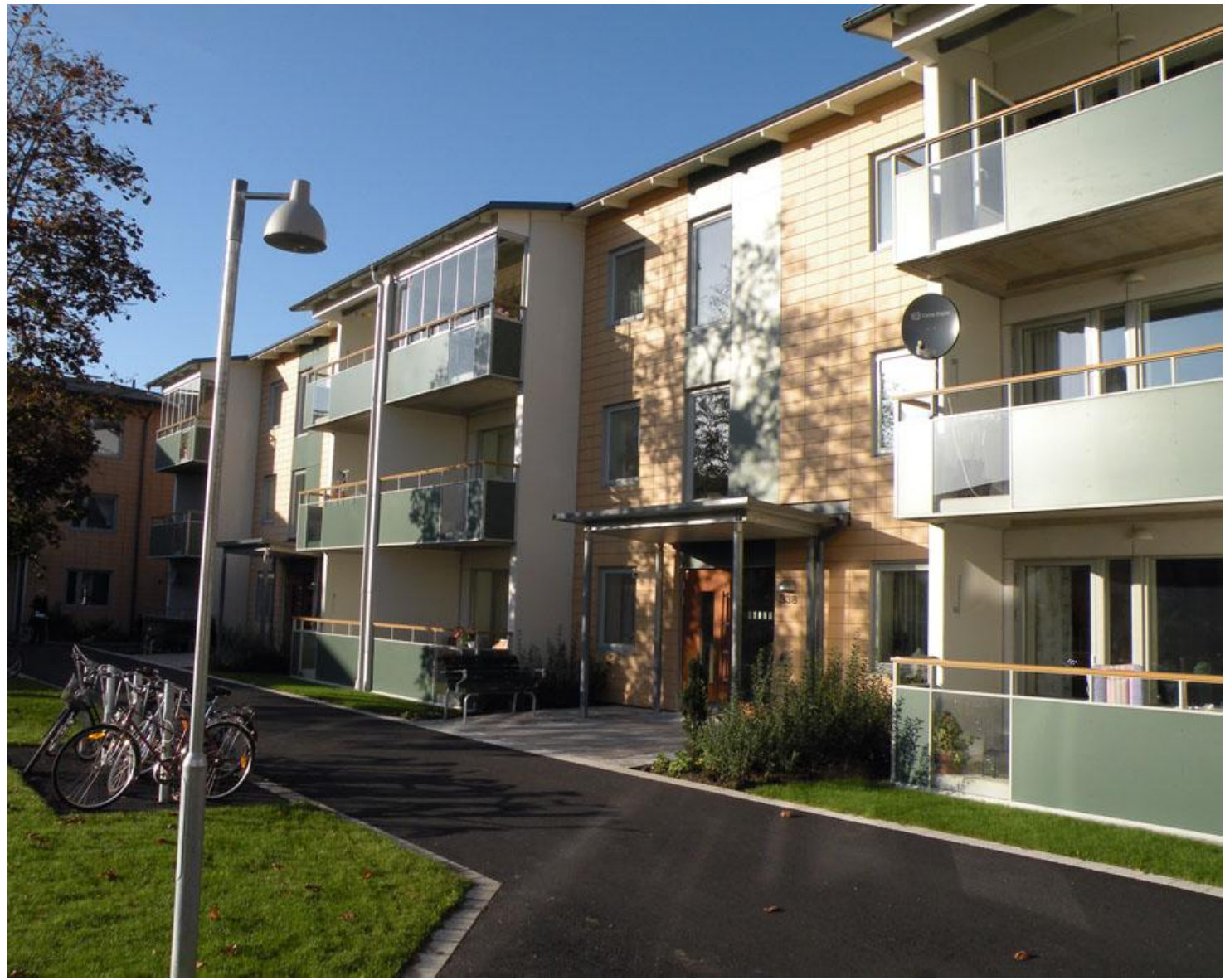

Figure 26: New balconies constructed outside of the buildings envelope in Brogården 
The previous ventilation system has been replaced with air-to-air heat exchanger units with $85 \%$ efficiency in heat recovery for each apartment (Figure 27). In very cold days, these units can also provide extra heat for the incoming air, using the wood-fueled district heating system as the heating source. It is estimated that this will happen approximately 10 days a year. The air inlets have been mounted on the living rooms and bedrooms walls and the out lets are in the kitchens and bathrooms. (Figure 28\&29)

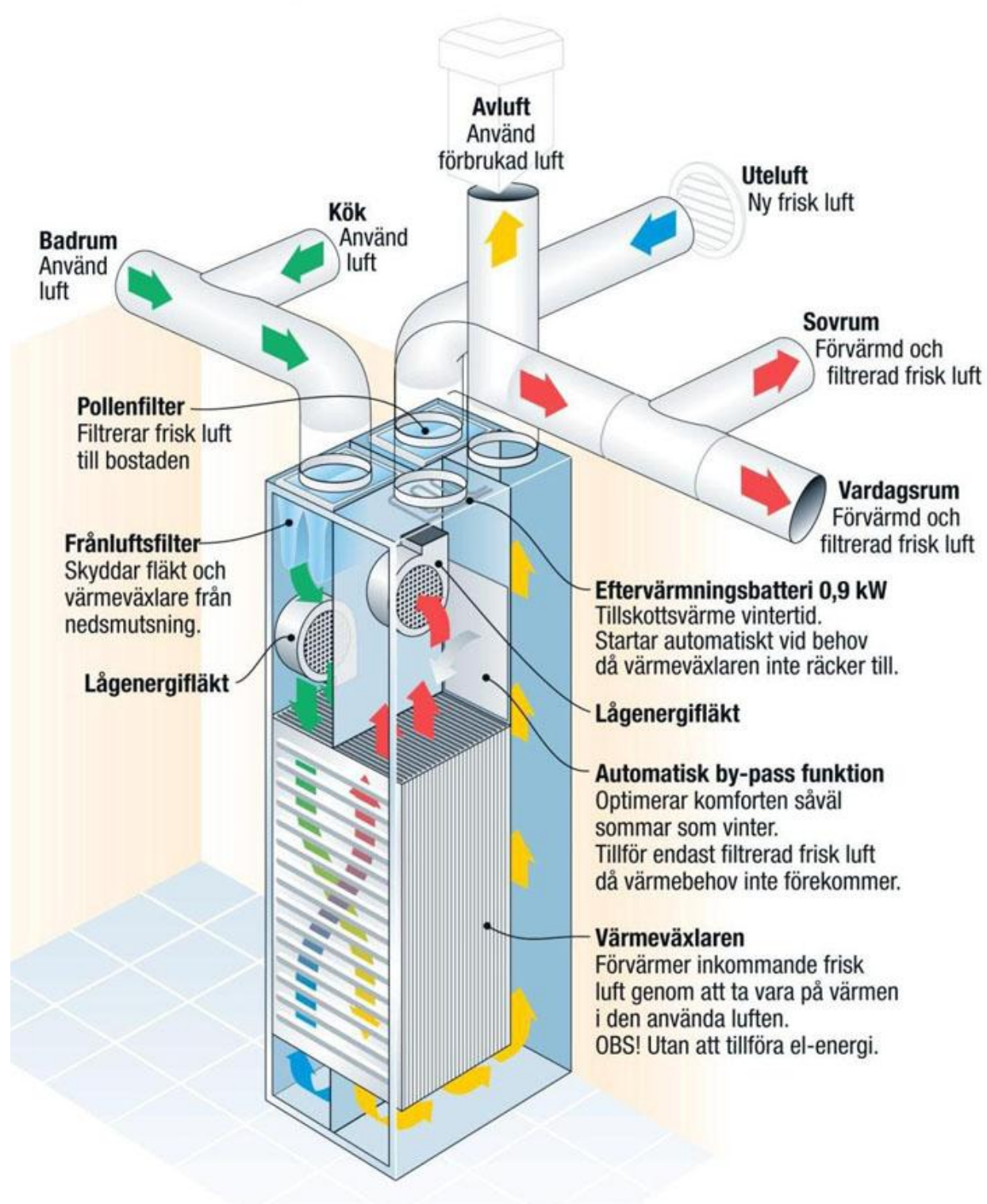

Figure 27: System of heat recovery in heat exchangers used in Brogården 


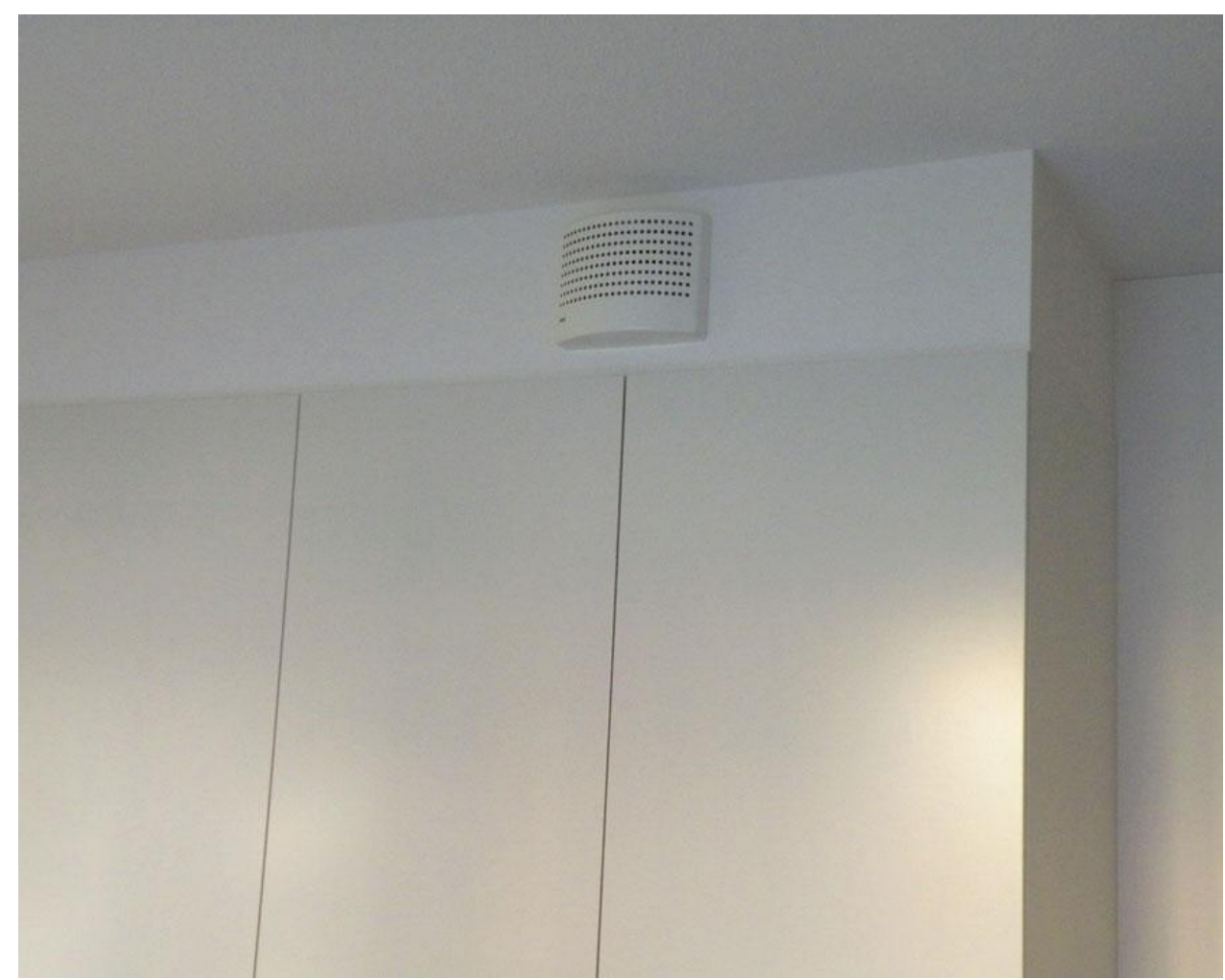

Figure 28: Air inlet in a bed room in Brogården after renovation

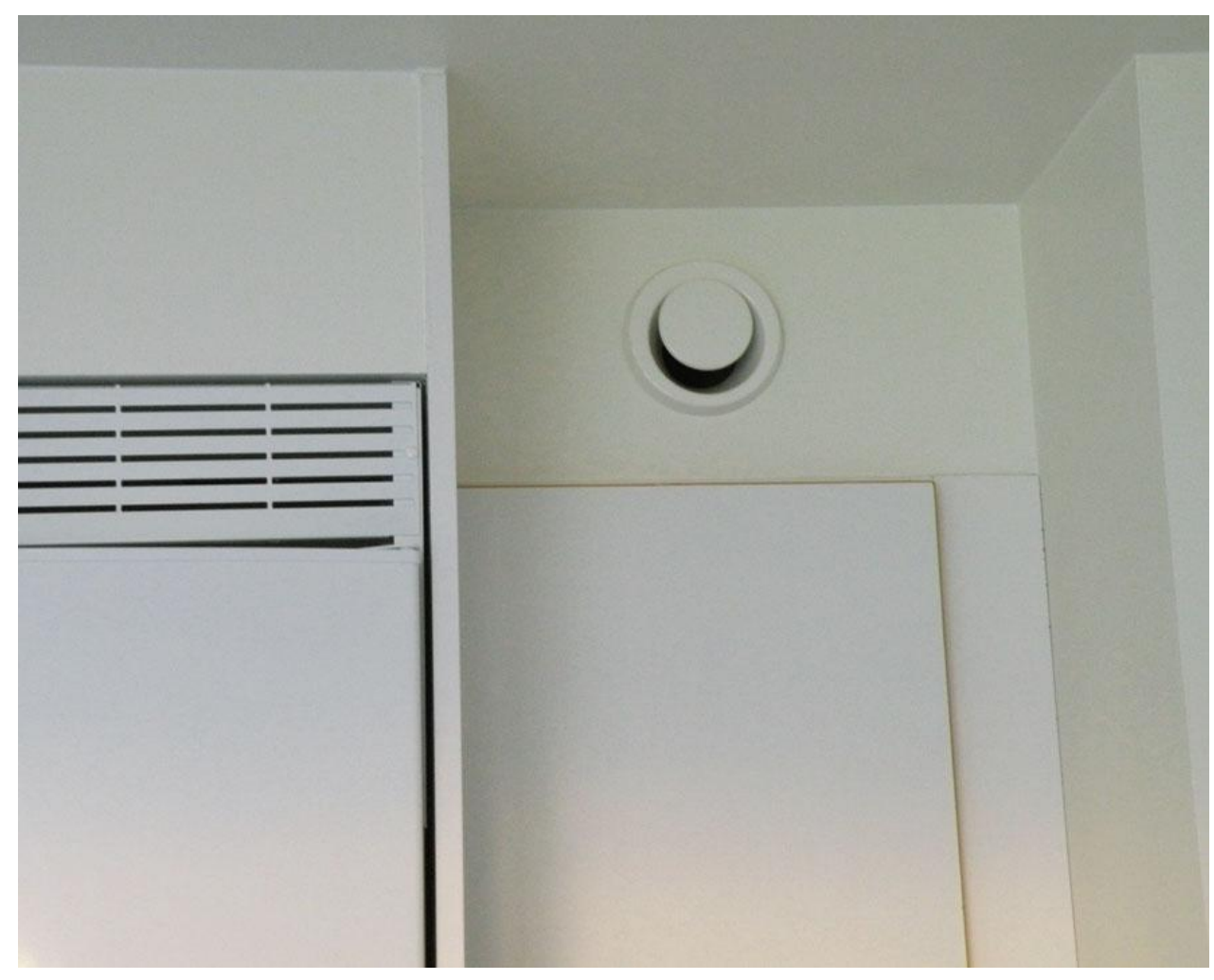

Figure 29: Air outlet in a kitchen in Brogården after renovation 
Each heat exchanger has a filter to reduce dust and air pollutants inside the flats, which should be changed once a year. The air tightness of 6 apartments were measured by SP before the renovation and the average value of the air leakage was measured $2 \mathrm{l} / \mathrm{s}, \mathrm{m}^{2}$ at an air pressure of $+/-50$ pa. The joints between the prefabricated concrete elements and the gaps around window frames were traced as the most critical points regarding air leakage. The same measurement was done after the renovation and the average value was $0.19 \mathrm{l} / \mathrm{s}, \mathrm{m}^{2}$ at the same air pressure.

The housing company has equipped the apartments with low-energy household appliances and low-flow toilets and fixtures. Furthermore, domestic hot water and household electricity will be individually metered and billed. This would increase the households' consciousness and reduce their energy consumption. After the renovation almost $60 \%$ of the apartments will be accessible by low-energy elevators, as part of an EU funded project. These elevators store energy from a downward motion to help with the subsequent upward motion.

\subsection{Comparison of the cases}

Table 2 provides some figures to compare the status of buildings after and before the renovation and also to compare the efficiency of applied measures in the two projects.

\begin{tabular}{|c|c|c|}
\hline & Gårdsten & Brogården \\
\hline Average indoor temperature & $21^{\circ} \mathrm{C}$ & $22^{\circ} \mathrm{C}$ \\
\hline Total energy consumption & 325 & 216 \\
\hline D.H. + El + H.W. & $\left(\mathrm{kwh} / \mathrm{m}^{2}\right.$, year $)$ & $\left(\mathrm{kwh} / \mathrm{m}^{2}\right.$, year $)$ \\
\hline Total energy consumption & 213 & 86 \\
\hline D.H. + El + H.W. & $\left(\mathrm{kwh} / \mathrm{m}^{2}\right.$, year $)$ & $\left(\mathrm{kwh} / \mathrm{m}^{2}\right.$, year $)$ \\
\hline District heating saving $\left(\mathrm{kwh} / \mathrm{m}^{2}\right.$, year $)$ & $270-160=110$ & $157-37=120$ \\
\hline Electricity saving $\left(\mathrm{kwh} / \mathrm{m}^{2}\right.$, year $)$ & $55-53=2$ & $39-28=11$ \\
\hline Water saving & $30 \%$ & $15 \%$ \\
\hline Operation costs saving & $210 \mathrm{SEK} / \mathrm{m}^{2}$,year & N/A \\
\hline Reduction of $\mathrm{CO}_{2}$ emissions & $\mathrm{N} / \mathrm{A}$ & $22 \mathrm{~kg} / \mathrm{m}^{2}$, year \\
\hline Total renovation costs & $5000 \mathrm{SEK} / \mathrm{m}^{2}$ & $13600 \mathrm{SEK} / \mathrm{m}^{2}$ \\
\hline Total costs for energy efficiency measures & $300 \mathrm{SEK} / \mathrm{m}^{2}$ & $1360 \mathrm{SEK} / \mathrm{m}^{2}$ \\
\hline
\end{tabular}

Table 2: Comparison of some results in Gårdsten and Brogården 


\section{Analysis of the cases}

As it was previously explained in section 1.6, in this part the cases are analysed based on the criteria of robust design (concerning user-oriented and climate-oriented design approaches) with regard to changes in some major factors affecting building's energy performance (Table 3). According to our studies and aforementioned definitions, an ideal robust design deals with reduced vulnerability to any unforeseen situation and thus a thorough robustness analysis entails a comprehensive study of future circumstances. However, among different factors influencing energy efficiency, some of them seem to be more essential and more likely to face uncertainties during building's lifetime including:

- Household appliances (using new appliances due to different lifestyles etc.)

- Occupant behavior (unexpected patterns of energy consumption)

- Maintenance support (Changes in building management etc.)

- Energy sources (Introducing different energy supplies due to cost etc.)

- Technical measures (issues related to availability of sophisticated systems)

- Envelope quality (physical changes due to issues such as aging)

- Climatic conditions (issues such as global warming etc.)

Consequently, for enhanced robustness in a renovation project, the design could be analyzed by studying alteration in these factors. Furthermore, among other criteria, adaptability of systems and redundancy of measures as two general qualities affecting robustness of systems, regarding climate-oriented design, preference for passive techniques and concerning users-building interface, users control over IAQ, Transparency of systems to users and facility of maintenance have been chosen as the main robustness criteria in the analytical framework.

Adaptability of design is an important characteristic which could be analysed from different aspects. For example concerning energy performance of a building, adaptability to other energy sources in the future due to external changes or to highly different outdoor temperatures due to climate change seems reasonable and redundancy of systems provides the opportunity of using alternative systems in case of failure or dissatisfaction. Concerning passive techniques, thermal exchange of a building which has a direct impact on its energy performance and the main methods of heat transfer in the cases have been mainly noticed in the analysis. Thermal insulation, thermal mass, U-value of windows, and thermal bridges affect heat transfer through conduction while preheating/cooling of incoming air, heat recovery of exhaust air (cold days)/free cooling of the building through ventilation of exhaust air (warm days) and air tightness of spaces are the major ways to avoid heat loss/gain through convection. Heat transfer through radiation can be controlled by measures influencing solar gain (cold days) and sun shading (warm days). Users control over IAQ deals with users satisfaction and their thermal comfort while transparency of systems to users makes it easier for the inhabitants to better un- 
derstand the systems and interact with them and prevents misuse of systems. Last but not least, facility of maintenance makes maintenance tasks more affordable and feasible for building management and can greatly affect time and energy savings.

Since EE buildings are characterized by focusing on three major issues of user comfort, environmental impact and energy cost, the relation between these issues and the aforementioned factors and criteria has been presented in the following diagram (Figure 30).

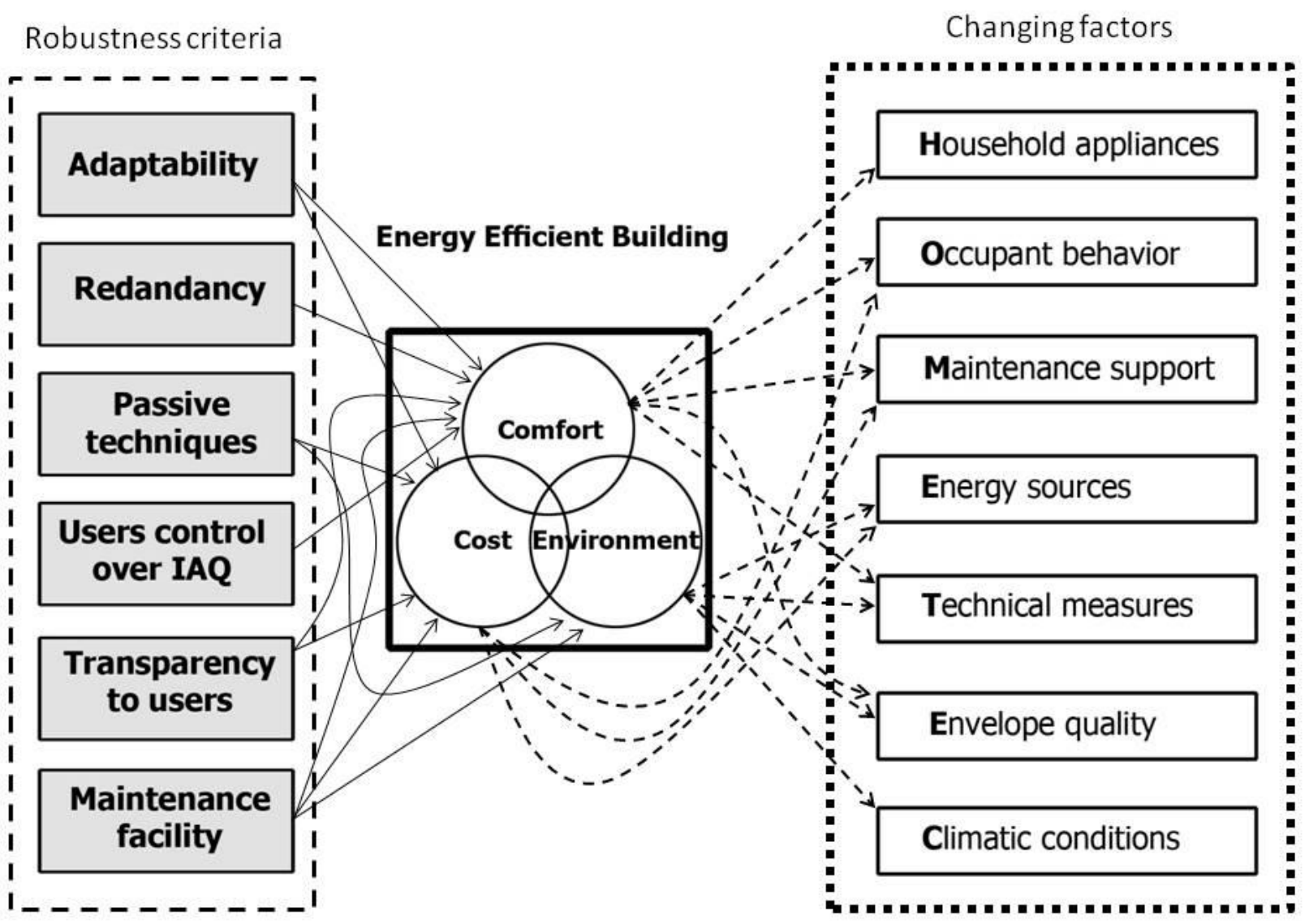

Figure 30: Relation between main objectives of EE buildings, robustness criteria and HOMETEC factors 


\section{Gårdsten}

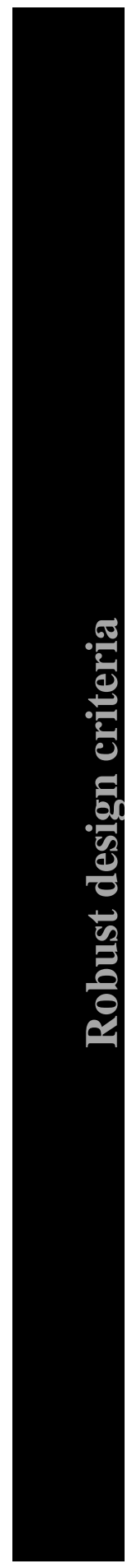

Adaptability of
systems

Redundancy of
measures
passive techniques

$\begin{aligned} & \text { Users control } \\ & \text { over IAQ }\end{aligned}$
IA
outdoor climates $(\mathrm{C}),(\mathrm{O})$

- Technical issues of adapting preheatsources (ES),(M)

+ Possible use of electricity based systems for heating/cooling $(\mathrm{C}),(\mathrm{O})$ provided in the apartments $(\mathrm{O}),(\mathrm{H})$

+ Preheating of incoming air through glazed balconies in high-rises (C) living rooms facing south $(\mathrm{C})$ and operable blinds and curtains (C) envelope $(\mathrm{C}),(\mathrm{T})$

- Apartments not very well air tight (C),(T) balconies with no air lock (High-rises) (O), (C)

+ Operable windows $(\mathrm{C})$

+ Operable glazing panels in balconies

(C)

+ Adaptable indoor temperature $(\mathrm{O})$

+ Blind curtains to control daylight $(\mathrm{C})$

- Possible unnecessary use of glazed balconies with extra heating in cold days $(\mathrm{O}),(\mathrm{H})$
+ Glazed balconies adaptable to different ing/heating systems to alternative energy - Alternative heating/cooling devices not

+ Solar gain through larger windows in

+ Sun shading provided both by balconies

- Considerable heat loss through building

- Heat loss through entrances in the open

\begin{tabular}{|c|c|c|}
\hline $\begin{array}{l}\text { Transparency } \\
\text { of systems to } \\
\text { users }\end{array}$ & $\begin{array}{l}\text { + Radiating panels used for heating } \\
\text { (T),(M) } \\
\text { + Glazed balconies to preheat incoming } \\
\text { air (T),(M) } \\
\text { - The system of solar panels to preheat } \\
\text { hot water not easily understandable for } \\
\text { layman (T),(M) }\end{array}$ & $\begin{array}{l}\text { + Highly insulated building envelope } \\
+ \text { Air tightness of the spaces }(\mathrm{T}) \\
\text { - Mechanical ventilation and integration } \\
\text { with heating }(\mathrm{T}),(\mathrm{M})\end{array}$ \\
\hline $\begin{array}{l}\text { Facility of } \\
\text { maintenance }\end{array}$ & $\begin{array}{l}\text { - Technically sophisticated parts such as } \\
\text { solar panels preheating water or heating } \\
\text { air in the low-rise building facing south } \\
\text { not very easy and affordable to maintain } \\
\text { (T),(M) }\end{array}$ & $\begin{array}{l}\text { + Buildings dependent only on one tech- } \\
\text { nical system (heat exchanger) which has } \\
\text { only a filter to be changed per year } \\
\text { (M),(T) } \\
\text { - Constant need for technical maintenance } \\
\text { (T),(M) }\end{array}$ \\
\hline
\end{tabular}

+ Façade material can be easily replaced (C), (O)

Economic issues in case of performance loss in insulation material (EQ),(M)

+ Possible use of simple sources of energy such as candles for space heating due to highly insulated and air tight envelope (ES)

ack of fresh air in case of failure in heat

+ Highly insulated building envelope

(C),(T),(EQ)

+ Xenon gas-filled triple glazed windows (C), (T)

+ Well air tight apartments $(\mathrm{C}),(\mathrm{T}),(\mathrm{EQ})$

+ Solar gain through larger windows in

living rooms facing south, east or west (C) + Sun shading provided both by balconies and operable curtains $(\mathrm{C})$

+ Operable windows $(\mathrm{C})$

- Integration of heating and ventilation (T)

Table 3: Analysis of the cases based on the criteria of robust design and major factors of change
(H): Household appliances
(O): Occupant behavior)
(M): Maintenance support
(ES): Energy Sources
(T): Technical systems
(EQ): Envelope Quality
(C): Climatic conditions 
While respecting climatic issues, passive housing seems to be a safer solution due to highly insulated and well air tight envelopes, both cases could be at risk of energy performance reduction in case of unexpected situations in their life time. What seem to be common in both projects are issues related to availability of technical systems, redundancy of systems and feasibility of maintenance. Here providing some examples can clarify the related issues. In case of technical solutions such as solar panels, ease and cost of maintenance, as well as availability of the technique and its performance in relation with environmental factors can be questionable whereas energy efficiency in a long-term perspective through passive house method which is quite dependent on building fabric and details, could be vulnerable to issues such as performance loss of thermal insulation materials. Furthermore, since in the latter case fresh air is provided by the heat exchangers which are also responsible for space heating, a break down in these systems can result in lack of fresh air in these highly air tight apartments. As it has been indicated in the table a technical maintenance support is required in solar houses in order to keep the system efficient which makes the EE objectives vulnerable due to economic issues and in case of passive houses a constant maintenance is needed to ensure the system performance.

Although the criteria for robust design have been presented with the same level of significance in this table, it is possible to determine more effective factors and criteria by applying methods such as system design to find the leverage points of applied systems according to the specific characteristics of each project.

\section{Conclusion and further remarks}

This study aimed at a better understanding of robustness as a building characteristic, especially regarding energy efficiency measures, IEQ and users' comfort. The study indicates that robustness is a qualitative characteristic of systems, specifically buildings in this research, which is generally defined as the characteristic of measures by which the building or the system lives up to its design purpose in a real life situation. Consequently, this characteristic is closely related to adaptability of a building and its subsystems. A building can be assessed for robustness through different aspects such as robustness of structure and building elements, robustness of users' comfort and satisfaction and robustness of feasible operation and maintenance each of which could enhance robustness of the whole building as a unified system.

Particularly, for multi-family housing, design for robustness seems to be a characteristic which can enhance building sustainability from different points of view and support the functional purpose of buildings. Since both notions aim for more durable and reliable systems, design for robustness is quite in sync with sustainable architecture. Therefore, the concept could be applied to assess sustainability of design in a long-term perspective. According to this study 
robustness of a building and particularly multi-family housing, can be noticeably enhanced through user-centred and climate-oriented design approaches. This means that consideration of climatic issues and users' needs, behaviour and consumption pattern etc. play a major role in adaptability of buildings to probable future changes and users' comfort as a very initial purpose of housing architecture. These two approaches provide the designers with more comprehensive data to have more realistic predictions and prevent inaccurate assumptions and misestimation of design performance during modelling. However, this should be stressed that to achieve a robust design a comprehensive study should be done and many different factors influencing the adaptability of buildings to unforeseen situations should be carefully studied and investigated.

According to the case analysis, there are major factors influencing building's energy performance in a long-term perspective which should be analyzed in the design process in order to assess robustness of design and building's sustainability. These factors which are likely to face unforeseen situations during building's lifetime include: household appliances, occupants behaviour, maintenance support, energy sources, technical measures, envelope quality and climatic conditions (HOMETEC factors of change). On the other hand, aiming for a building with robust energy efficiency measures entails a design process with accurate assumptions in which criteria such as redundancy, adaptability, passive techniques and user-oriented solutions are taken into account.

It is also worth mentioning that in an architectural design, to achieve an acceptable or desirable result, there are several factors to be taken into account. In each project, it is the specific conditions and the particular context of the project that specifies which design criteria should be given the priority. Obviously, it would be too idealistic and in most cases unattainable to aim for a perfect building; however, as far as sustainable architecture is concerned, robustness of the building and its measures could be considered as an important characteristic to be planed for. Regarding the design criteria, robustness is quite in sync with sustainability of a building and related issues such as durability. An important point of the study to be stressed is that it could be understood from the case studies and some other literature that sometimes aiming for a robust design does not necessarily mean to achieve the most efficient performance of the building, especially in a short term perspective. For instance, regarding energy efficiency of a building, some measures seem to save more energy and thus more efficient, but concerning sustainability in a long-term perspective, not all of them are necessarily robust. Therefore in evaluation of a design or deciding for design characteristics, robustness and efficiency should not be misinterpreted.

Finally it is hoped that this research can provide architecture students, researchers and architects with sufficient information on the subject of design for robustness and encourage further studies in this area in order to develop this knowledge, specifically in energy efficient buildings, and to apply robust design criteria to have more adaptable buildings in the future. 


\section{References}

Andersson, P. (1997). Robustness of Technical Systems in Relation to Quality, Reliability and Associated Concepts. Journal of Engineering Design, 13.

Bokalders, Varis and Maria Block. (2010). THE WHOLE BUILDING HANDBOOK, How to Design Healthy, Efficient and Sustainable Buildings. London: Erthscan.

Borgegård, Lars-Erik and Jim Kemeny. (2004). Chapter 3. Sweden: High-rise housing for a lowdensity country. i R. v. R. Turkington, High-rise housing in Europe: current trends and future prospects (ss. 31-48). Delft University press.

Botta, M. (2005). Towards Sustainable Renovation, Three research projects. Stockholm: Royal Institute of Technology.

Botta, M. (2007). Issues and Actions for Sustainable Renovation. CIB World Building Congress, (s. 16). Cape town.

Boverket. (2010). The structure of the Swedish Government. Karlskrona: Boverket.

Brand, S. (1994). How Buildings Learn: What Happens After They're Built. New York: Viking Press.

(u.d.). Brogården: Passive housing technology in a renovation project. ECOEX.

Bullinger, Hans-Jörg, Wilhelm Bauer, Gunter Wenzel and Roland Blach. (2010). Towards user centred design (UCD) in architecture based on immersive virtual environments. Elsevier, 8.

Dalenbäck, J.-O. (2007). Training for Renovated Energy Efficient Social housing(TREES), Section 3 Case studies. Intelligent Energy -Europe programme, contract $n^{\circ}$ EIE/05/110/SI2.420021, 21.

de Dear, R.J., G.S. Brager and D. Cooper. (1997). Developing an Adaptive Model of Thermal Comfort and Preference. Final Report ASHRAE RP-884.

Diamantidis, D. (2009). Robustness of building in structural codes. COST Actions TU0601 and E55, (s. 8). Ljubljana.

Dutil, Y. D. (2011). Sustainable Buildings: An Ever Evolving Target. Sustainability, 22.

Faber, M. a. (u.d.). COST Action TU0601 - Robustness of structures : A summary.

Femenías, P. (2004). Demonstration Projects for Sustainable Building: Towards a Strategy for Sustainable Development in the Building Sector based on Swedish and Dutch Experience. Gothenburg: Chalmers University of Technology.

Femenías, P. a. (2011). Sweden: integrated strategies to overcome market barriers. 21. 
Femenías, Paula and Anke van Hal. (2009). Sustainable Housing Transformations: The Housing Association as a Change Agent for Environmental Innovation and Social Regeneration Two case studies. ENHR 2009 Prague Conference, (s. 24). Prague.

Freire-Gonzalez, J. (2011). Methods to empirically estimate direct and indirect rebound effect of energy-saving technological changes in households. Elsevier Sience, 9.

Gårdstensbostäder. (u.d.). Solar buildings in Gårdsten. Gothenburg: Gårdstensbostäder.

Groat, Linda and David Wang. (2002). Architectural research methods. Chichester: Wiley.

Hass, Reinhard and Peter Biermayr. (2000). The rebound effect for space heating; Empirical evidence from Austria. Elsevier Sience, 8.

Hasselaar, B. L. (2006). Climate Adaptive Skins: towards the new energy-efficient façade. Delft: WIT Press.

Högberg, L. H. (2009). Incentives for Improving Energy Efficiency When Renovating Large-Scale Housing Estates: A Case Study of the Swedish Million Homes Programme. sustainability, 17.

Janson, U. (2008). Apartment Building in Brogården, Alingsås SE. IEA SHC Task 37, Advanced Housing Renovation with Solar \& Conservation.

Janson, U. (2009). Renovation of the Brogården area to Passive Houses. Passivhus Norden, (s. 8). Gothenburg.

Juricic, S. (2011). ROBUSTNESS OF A BUILDING, Relationship between building characteristics and actual energy consumption and indoor health and comfort perception.

Kahraman, Z. E. (2010). Using user-centered design approach in course design. Elsevier, 6.

Laustsen, J. (2008). ENERGY EFFICIENCY REQUIREMENTS IN BUILDING CODES, ENERGY EFFICIENCY POLICIES FOR NEW BUILDINGS. Paris: international energy agency.

Leyten, J. L. (2005). Robustness of buildings and HVAC systems as a hypothetical construct explaining differences in building related health and comfort symptoms and complaint rates. Energy and Buildings, 7.

Leyten, Joe L., Stanley R. Kurvers and Jos van den Eijnde. (2009). Robustness of office buildings and the environmental Gestalt. Healthy Buildings (s. 4). Delft: Delft University of Technology.

Morrin, N. (2009). Brogården, Sweden. Skanska.

Nordström, C. (2005). Solar Housing Renovation, Gårdsten, Sweden. Gothenburg.

Pavard, B. J.-B. (2006). Design of robust socio-technical systems. 10.

Roggema, R. (2009). Adaptation to Climate Change: A Spatial Challenge. New York: Springer. 
Rosenlund, H. (2000). Climatic Design of Buildings using Passive Techniques. Building issues, (s. 24).

Simm, Stephen, David Coley and Pieter de Wilde. (2011). COMPARING THE ROBUSTNESS OF BUILDING REGULATION AND LOW ENERGY DESIGN PHILOSOPHIES. Proceedings of Building Simulation 2011 (s. 8). Sydney: 12th Conference of International Building Performance Simulation Association.

Sussman, G. J. (2007). Building Robust Systems an essay. Massachusetts Institute of Technology.

Wigington, L. (2008). One Year Later: Moving Existing Homes Toward Carbon Neutrality. Waynesburg: Affordable Comfort, Inc. (ACI).

\section{Websites:}

http://www.torinmonahan.com/papers/Inventio.html (Visited December 2011)

http://www.aisc.org/content.aspx?id=19816 (Visited November 2011)

http://www.sabo.se (Visited October 2011)

http://www.partridge.com.au/index.php/aboutus-resources/237-the-sustainability-of-beauty

(Visited April 2012)

http://en.wikipedia.org/wiki/Rebound_effect_(conservation) (Visited April 2012)

http://en.wikipedia.org/wiki/Million_Programme (Visited September 2011)

http://en.wikipedia.org/wiki/User-centered_design (Visited February 2012) 